\title{
Article \\ Experimental Study on Motion Characterisation of CALM Buoy Hose System under Water Waves
}

\author{
Chiemela Victor Amaechi ${ }^{1,2, *}$, , Facheng Wang ${ }^{3, *}$ and Jianqiao $\mathrm{Ye}^{1, *}$ \\ 1 Department of Engineering, Lancaster University, Lancaster LA1 4YR, UK \\ 2 Standards Organisation of Nigeria (SON), 52 Lome Crescent, Wuse Zone 7, Abuja 900287, Nigeria \\ 3 Department of Civil Engineering, Tsinghua University, Beijing 100084, China \\ * Correspondence: c.amaechi@lancaster.ac.uk or chiemelavic@gmail.com (C.V.A.); \\ wangfacheng@tsinghua.edu.cn (F.W.); j.ye2@lancaster.ac.uk (J.Y.)
}

check for updates

Citation: Amaechi, C.V.; Wang, F.; Ye, J. Experimental Study on Motion Characterisation of CALM Buoy Hose System under Water Waves. J. Mar. Sci. Eng. 2022, 10, 204. https:// doi.org/10.3390/jmse10020204

Academic Editor: Kostas

Belibassakis

Received: 14 November 2021

Accepted: 30 January 2022

Published: 2 February 2022

Publisher's Note: MDPI stays neutral with regard to jurisdictional claims in published maps and institutional affiliations.

Copyright: (C) 2022 by the authors. Licensee MDPI, Basel, Switzerland. This article is an open access article distributed under the terms and conditions of the Creative Commons Attribution (CC BY) license (https:// creativecommons.org/licenses/by/ $4.0 /)$.

\begin{abstract}
The application of marine bonded hoses has increased in recent times, due to the need for more flexible conduits and flexible applications in the offshore industry. These marine structures include Catenary Anchor Leg Moorings (CALM) buoys and ocean monitoring buoys. Their attachments include floating hoses, submarine hoses and submarine cables. However, the structural performance challenges of a CALM buoy system from its hydrodynamics water waves and other global loadings, have led to the need for this investigation. In this study, a detailed presentation on the motion characterisation of the CALM buoy hose system is presented. The CALM buoy is a structure with six degrees of freedom $(6 \mathrm{DoF})$. A well-detailed experimental presentation on the CALM buoy hose model conducted in Lancaster University Wave Tank is presented using three novel techniques, which are: a digital image captured using Imetrum systems, using an Akaso 4K underwater camera, using wave gauges arranged in a unique pattern and using underwater Bluetooth sensors. The buoy model was also found to respond uniquely for each motion investigated under water waves. The results showed that the higher the profile, the higher the response of the buoy. Thus, this study confirms the existence of flow patterns of the CALM buoy while floating on the water body.
\end{abstract}

Keywords: ocean waves; hydrodynamics; catenary anchor leg mooring (CALM) buoy; marine riser; marine hose; motion characterisation; CALM buoy model test; ocean engineering; offshore structure; floating offshore platform (FOS)

\section{Introduction}

The need for more energy resources from fossil fuels has led to the development of new floating offshore structures (FOS) for more explorations in different water depths [1-6]. These structures are induced by water waves from shallow waters to intermediate waters and deep waters [7-13]. This has led to the increase in the trend for the need for lighter marine structures and more flexible ones that can be easier for fluid transportation, such as marine risers [14-18]. Several innovations on FOS have been reported in ocean engineering, particularly Catenary Anchor Leg Moorings (CALM) buoys [19-26]. These buoys are attached with floating hoses, submarine hoses and reeling hoses. The stability of the buoy will also determine the lifespan of the marine buoys and mooring lines. However, these marine bonded hoses are challenged with different structural issues, despite being very efficient in fluid delivery [27-33].

Thus, there is the need to investigate the motion characterisation of CALM buoy systems experimentally. Currently, the design guidelines for these marine hoses are based on industry standards like API 17K, GMPHOM OCIMF 2009, DNVGL and ABS specifications [34-39]. These hoses have some cons, ranging from a shorter service life, kinking, matrix cracking, damage from vessel motion, damage from hose response (snaking phenomenon and perturbations), damage from impact (line clashing), damage from disconnection (accidental operation) and vibration to other structural challenges [40-44]. On the 
other hand, the buoys have motion responses that are relatively due to the wave loads and hydrodynamic properties on the FOS [45-50]. In real-life applications of offloading and loading operations in offshore oil terminal systems are made of single point moorings (SPM), which are made up of three main mooring configurations: Articulated Single Point Moorings (ASPM), Single Anchor Leg Moorings (SALM) and Catenary Anchor Leg Moorings (CALM) [51-55]. The SPM Buoy is a buoy that is securely anchored to the seabed by multiple mooring lines/anchors/chains, allowing liquid petroleum product cargo to be transferred. A bearing system on the buoy allows a section of it to rotate around the moored geostatic portion. The vessel will freely weathervane all around the geostatic section of the buoy while it is moored to this rotating part of the buoy with a mooring attachment. The buoy body, mooring and anchoring components, product transfer system and ancillary elements make up the SPM system. Static legs connected to the seabed under the ocean secure the buoy body in place. The body is attached to the offloading/loading tanker by a revolving portion above the water level. The Main Bearing connects these two sections. For this same arrangement, the moored tanker will weathervane freely around the buoy to find a secure spot. The definition of the buoy is determined by the form of bearing used and the separation of the rotating and geostatic components. The buoy's size is determined by the amount of counter buoyancy needed to keep the anchor chains in place, and the anchor chains are determined by environmental factors and the size of the vessel.

Some experimental investigations have been conducted on the CALM buoy by varying the buoy skirts [56-60]. Edward \& Dev [60] accessed the motion response of the CALM buoy with some empirical estimation on the viscous damping. Cozijn et al. [61] conducted an experiment using a 1:20-scaled CALM buoy model and found drag coefficient values and damping data for pitch, roll and heave motions. These were also used to compute the coefficient of additional mass, which is 1.5 for CALM buoy hoses [61,62]. However, similar studies on buoy motion have been conducted using computational fluid dynamics (CFD) [63-65]. In principle, CFD models are developed using different discretisation methods like interpolating element-free Galerkin (IEFG), the Boundary Element Method (BEM) and the Ciarlet-Raviart mixed finite element method (FEM) and finite volume methods [66-68]. Figure 1 shows a CALM buoy maintained by Bluewater with two hawsers attached to the FPSO for loading/offloading operations.

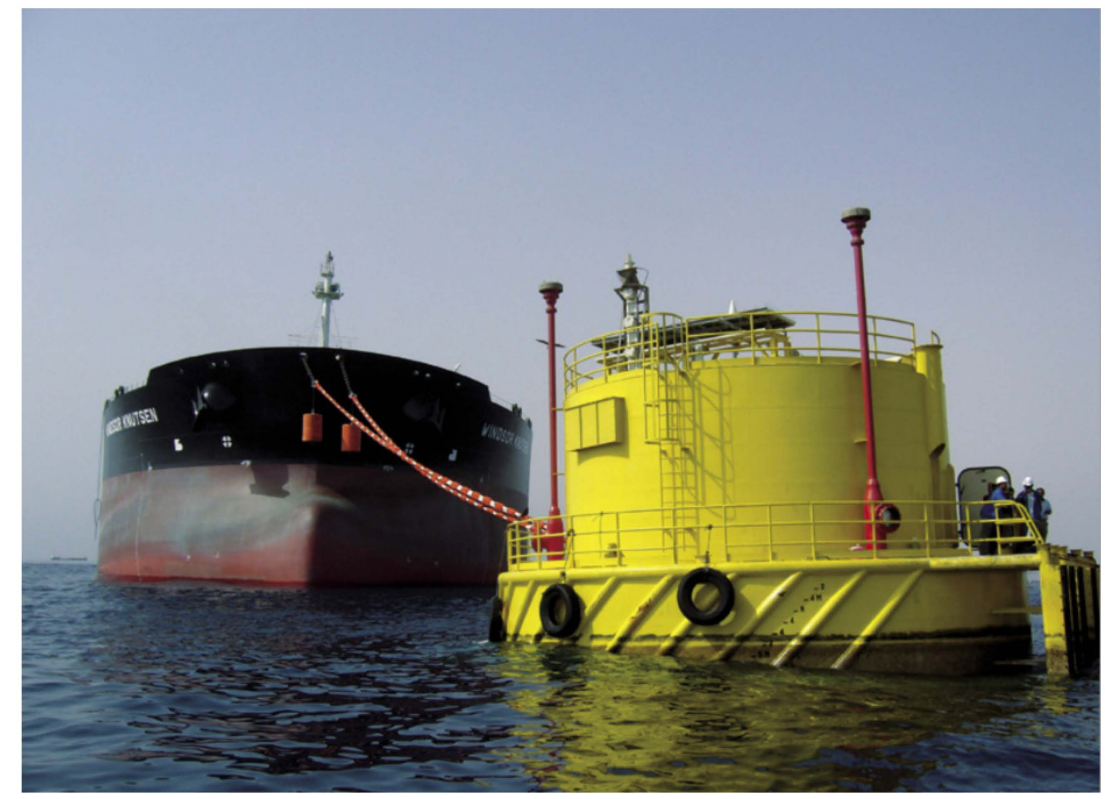

Figure 1. CALM buoy with two hawsers attached to the FPSO for loading and offloading operations (reproduced, with permission, courtesy: Bluewater; Source: Bluewater, [69]). 
In this article, an experimental investigation was conducted on the motion characterisation of a CALM buoy under water waves. Section 1 presents some introduction to this buoy study. Section 2 presents the experimental model of the CALM buoy and the materials and methods. Additionally, some assumptions on the buoy with a skirt and buoy with the hose model were presented. Section 3 presents the results and discussion, while the concluding remarks on the CALM buoy study are given in Section 4. The CALM buoy is a floating buoy designed to operate in six degrees of freedom (6DoFs). It is usually attached to a tanker via hawsers and a floating hose during loading operations.

\section{Materials and Methods}

The experimental modelling aspect is presented in this section on the materials utilised in this experiment and the methodology. The materials included the buoy, submarine hoses, mooring lines and cameras, as discussed in the subsequent subsections.

\subsection{Experimental Setup}

For the experiment, the Lancaster University Wave Tank facility was used in all the experimental investigations. The CALM buoy test model was first tested for buoyancy, and leakage; then, it was properly ballasted. It was then positioned $5.5 \mathrm{~m}$ from the wave maker along the central axis of the wave tank. Figure 2 is the flow direction across the CALM buoy model's hull. The buoy model was then moored using 4 steel chain mooring lines, and 4 wave gauges were attached to the buoy skirt, as in Figures 7-10. The steel chain mooring lines were later replaced with polyester lines, as they suitable. The anchors were initially scree points on the floor of the wave tank. It was later replaced by using some marked " $5 \mathrm{~kg}$ " weights as anchors for each of the 4 moorings. Video recordings were also collected for each run using an underwater camera. It recorded the behaviours of the hoses (submarine and floating) and the CALM buoy for different frequencies. The experimental setup shows the Lancaster University wave tank in Figure 3. The first set of the experiment was carried out using a flat seabed for different frequencies. Wave gauges were attached to obtain the readings using a setup with LabView NXG 5.1. LabView was interfaced with a NI-DAQmx Device called National Instruments DSUB Model NI 9205. End fittings were connected at both ends of the two hoses connected to the buoy model underneath it (submarine hoses) and one hose on the side (floating hose). Mooring lines made of 20-mm-diameter steel chains were used, and one end was anchored to the floor while the other end was to the skirt of the model for the CALM buoy. The methodology for the experiment will be presented in Section 2.10.

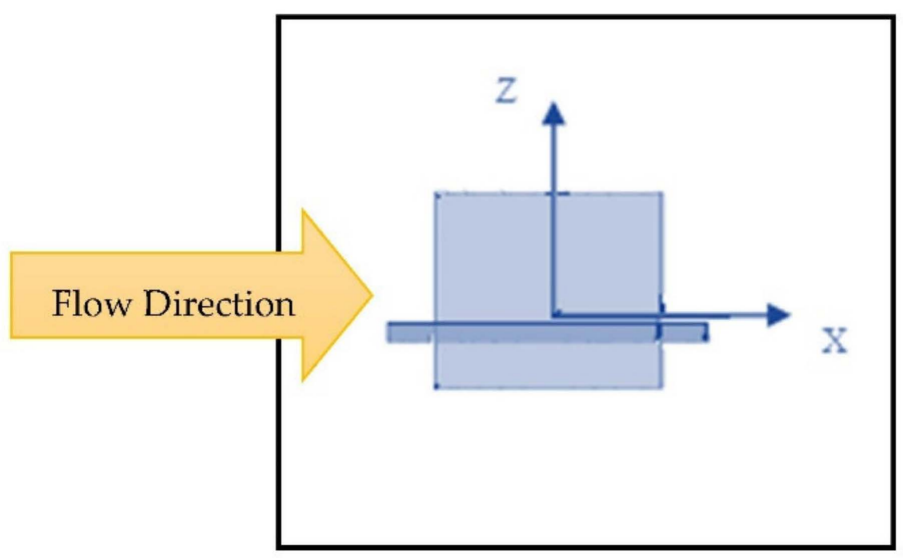

Figure 2. Illustration of the flow direction across the CALM buoy model's hull. 


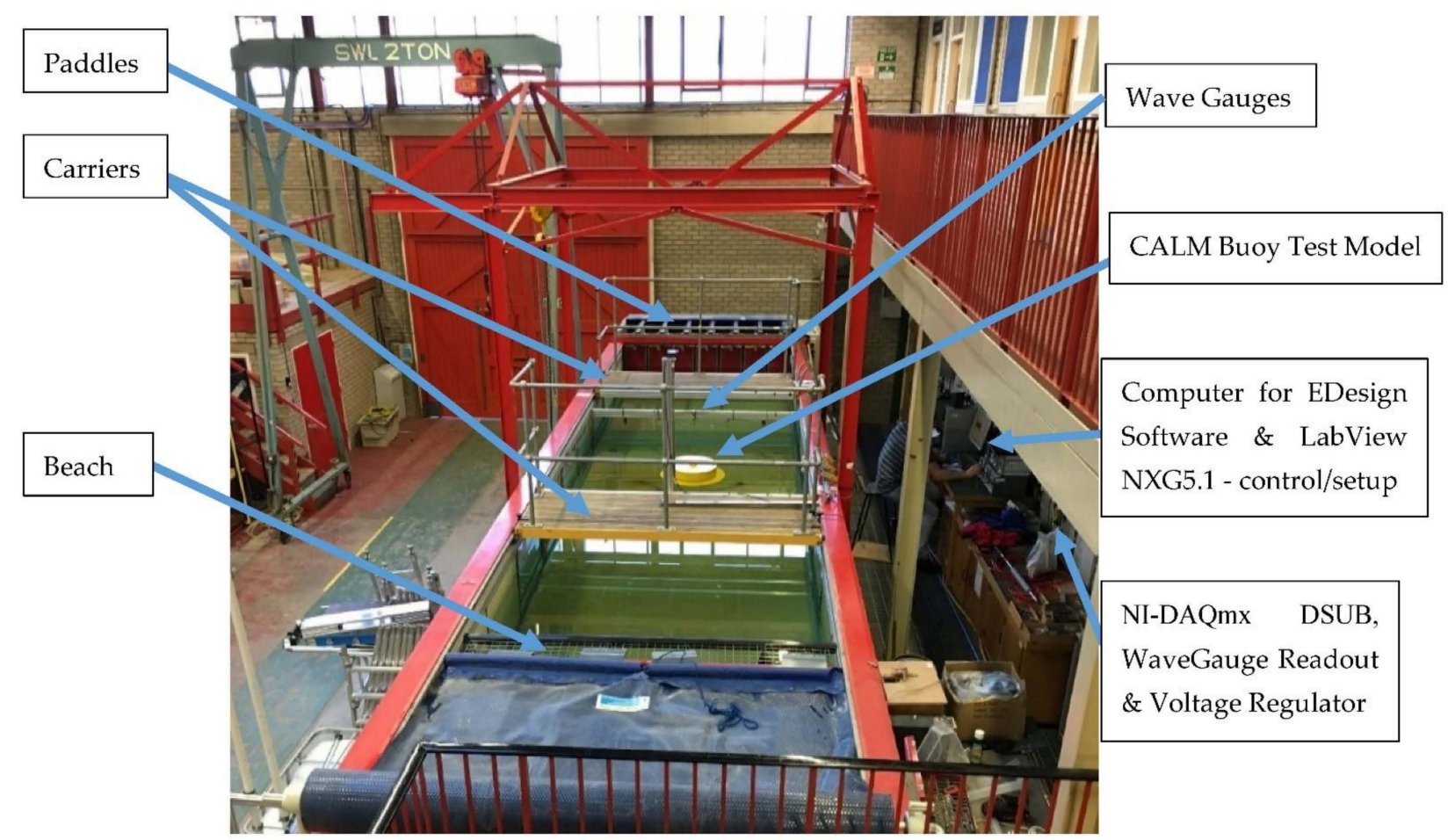

Figure 3. Test basin at the Lancaster University Wave Tank facility showing the location of the buoy and wave gauges used in the experiment.

\subsection{Lancaster University's Wave Tank}

The experimental setup for the CALM buoy model is shown in Figure 3. The detailed setup for other components are presented in Sections 2.3-2.10. The dimensions of the wave tank measure at $15 \mathrm{~m}$ lengthwise, $2.5 \mathrm{~m}$ in width and $1.7 \mathrm{~m}$ in depth. A schematic of the key features, dimensions, wave tank details, wave gauge layout, model supporting structures and model mounting area on the wave tank is illustrated in Figure 4 . The beach contains a $2.5-\mathrm{m}$-lengthwise space, leaving a 12.5-m-lengthwise space available for use in the experiments. Also, the depth was adjusted to $1.0 \mathrm{~m}$. The waves are generated using force feedback control through seven (7) flappy-type paddles, designed by Edinburgh Designs, UK [70]. Each of the paddles has the capacity to produce sinusoidal waves with a frequency range of $1.5-0.5 \mathrm{~Hz}$, while the amplitudes are as high as $100 \mathrm{~mm}$. They are also capable of creating data files from both irregular and regular waves, depending on the input configuration. The wave tank facility has been used in validated studies [71-74].

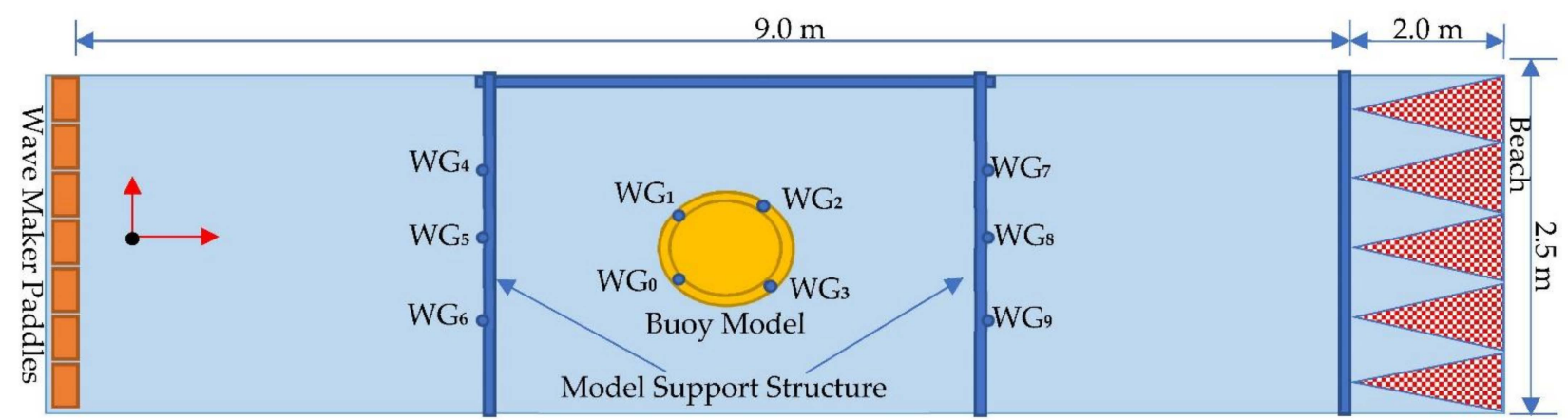

Figure 4. Schematic of the key features, dimensions, wave tank details, wave gauge layout, model supporting structures and model mounting area of the Lancaster University Wave Tank. 


\subsection{The Buoy Model}

The buoy model is developed by considering some model assumptions, including that the buoy is cylindrical, with a skirt attached to it and the skirt has a thin thickness from solid plates. The fabrication of the buoy model was obtained using the modelling rules. The parameters for the buoy applied in the design analysis are presented in Table 1 . The model was scaled down, and the model test was constructed with two submarine hoses attached underneath the buoy and one floating hose on the side, as shown in Figure 5a,b. The results of the motion response of the CALM buoy carried out experimentally are presented in Section 3, respectively. The fabrication of the buoy model was carried out in Lancaster University Engineering Department's Mechanical Workshop. The considerations used included light metallic buoy materials, buoyancy, draft line, ballasting and scaledmodelling rules. To ballast the buoy, an opening was created at the top which was used to fill the ballast. The ballasting material used was a measured amount of sharp sand. The parameters for the buoy used in the experimental study are presented in Table 1.

Table 1. Parameters of the model test buoy.

\begin{tabular}{lc}
\hline Parameters & Model Test \\
\hline Shape of buoy & Cylindrical \\
\hline Depth of Water $(\mathrm{m})$ & 0.90 \\
\hline Diameter of Skirt $(\mathrm{m})$ & 0.68 \\
\hline Draft size $(\mathrm{m})$ & 0.15 \\
\hline Mass of Buoy $(\mathrm{kg})$ & 0.25 \\
\hline Buoy's Height $(\mathrm{m})$ & 0.20 \\
\hline Diameter of Buoy's body $(\mathrm{m})$ & 0.50 \\
\hline
\end{tabular}

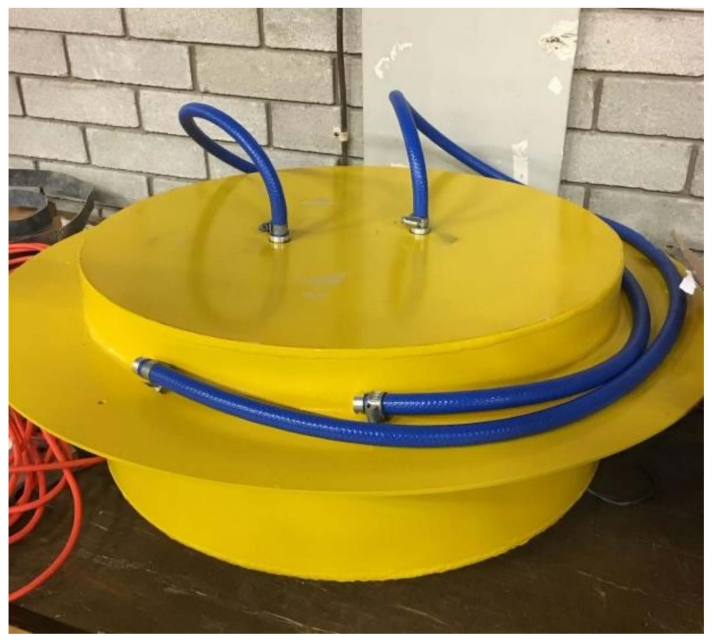

(a)

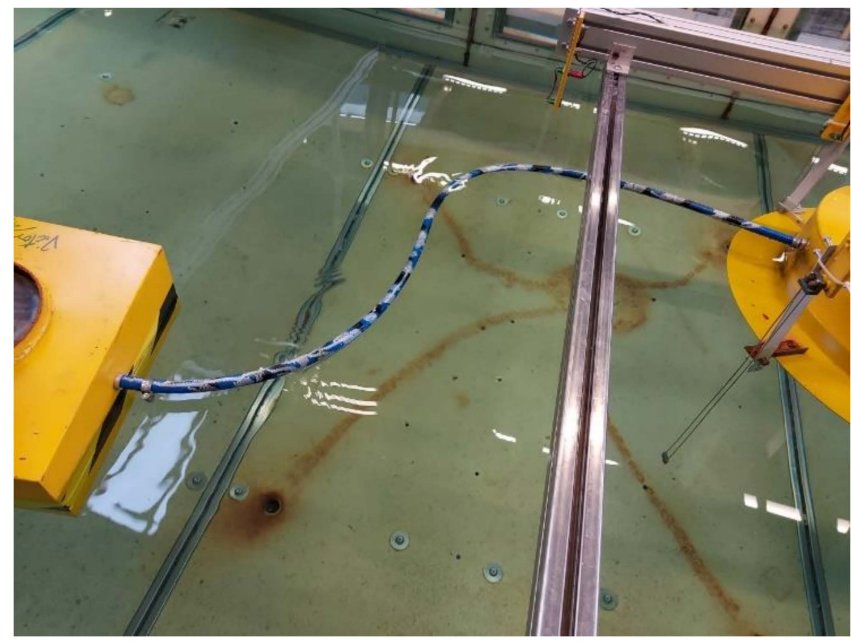

(b)

Figure 5. Images of (a) the CALM buoy test model fabrication showing a skirt with the underneath hoses and (b) the buoy model with floating hoses and attached wave gauges on the buoy skirt.

\subsection{Mooring Lines \& Fittings}

The CALM buoy system was moored with two sections of steel chain moorings. The mooring arrangement was made up of four (4) mooring lines modelled as catenary mooring lines. The moorings are set up on the buoy and fixed via fairings attached on its skirt, as seen in Figure 6. One end of the mooring line was attached to the skirt of the cylindrical buoy, while the other end was anchored to the seabed. The schematic for the setup of the 
model using chain moorings is presented in Figure 7. The mooring lines had the same stiffness and were $90^{\circ}$ apart, as depicted in Figure 7.

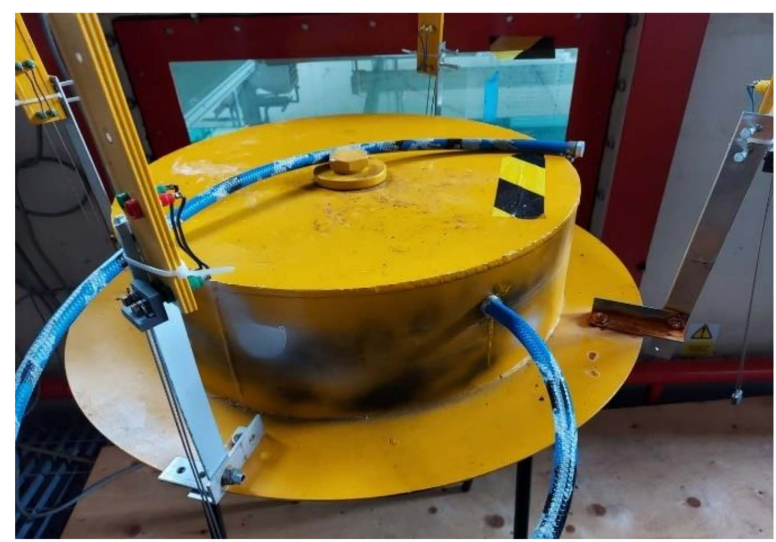

(a)

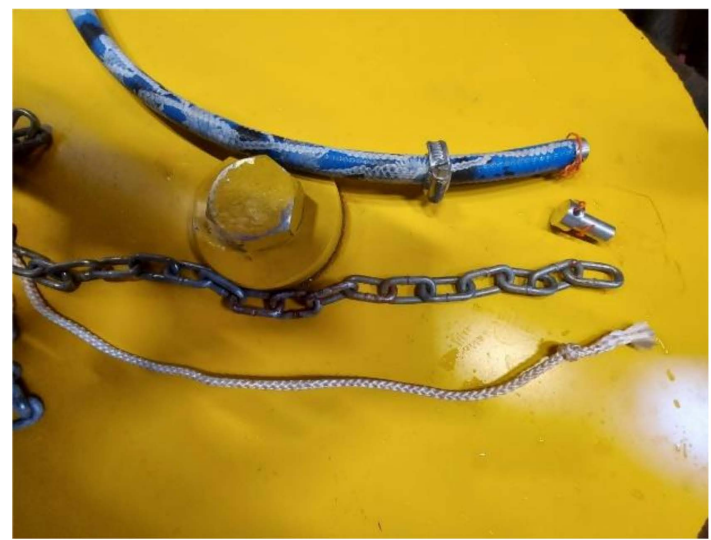

(b)

Figure 6. Setting up the moorings on the buoy model, showing (a) the skirt with attached wave gauge fittings by mooring line fairleads, and (b) the polyester rope and the chain mooring lines used on the moorings during the experiment.

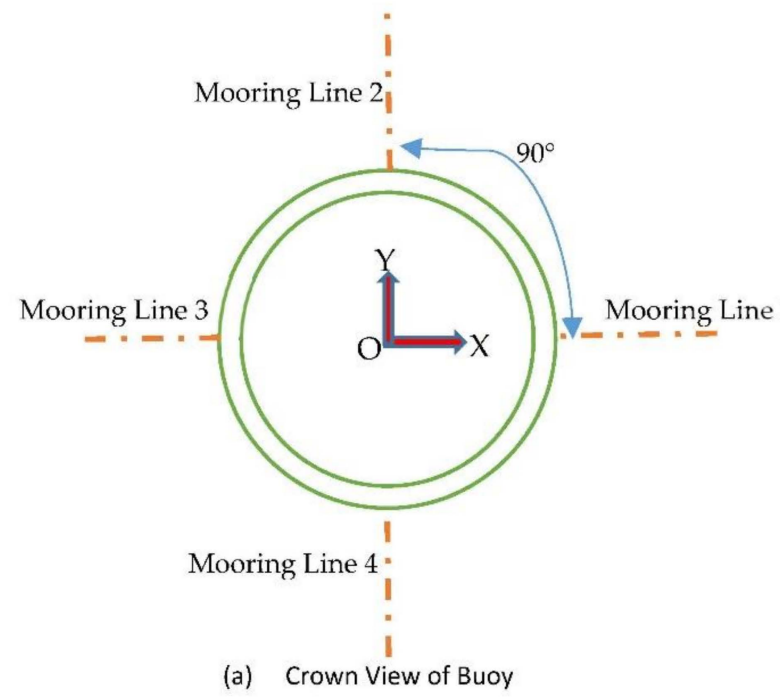

Figure 7. Arrangement of moorings showing (a) a crown view of the buoy and (b) a side elevation view of the buoy.

\subsection{Hoses and End Fittings}

A floating hose was also attached on the side to investigate the behaviours of floating hoses, such as snaking. The hose material used in the model was about $20 \mathrm{~mm}$ in diameter, with minimal flexible stiffness, to depict an offshore hose behaviour. Four end fittings were also prepared for the hoses, as shown in the Figures 6 and 8a. As can be observed in this study that the material chosen for the floating hoses reflects real-life applications [69]. These fittings are to ensure that the investigation on the hose behaviour relative to the water waves can be investigated in real time. 


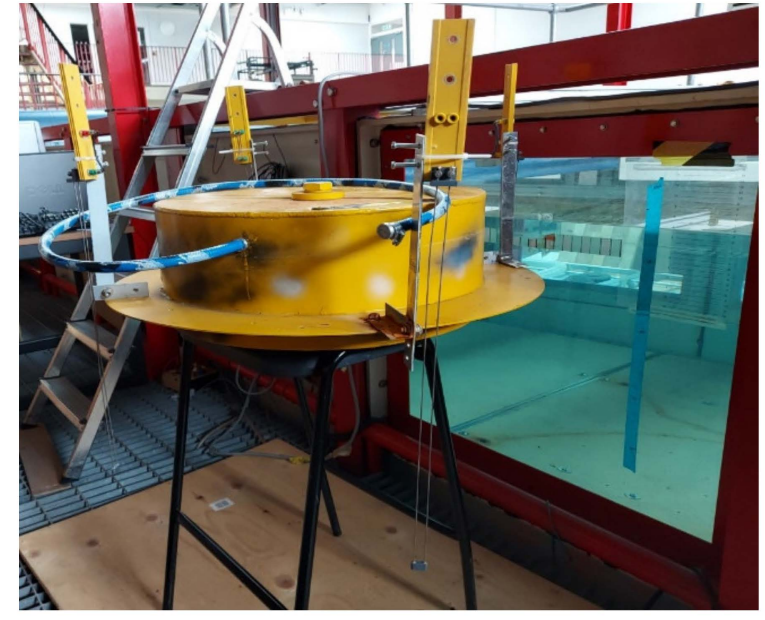

(a)

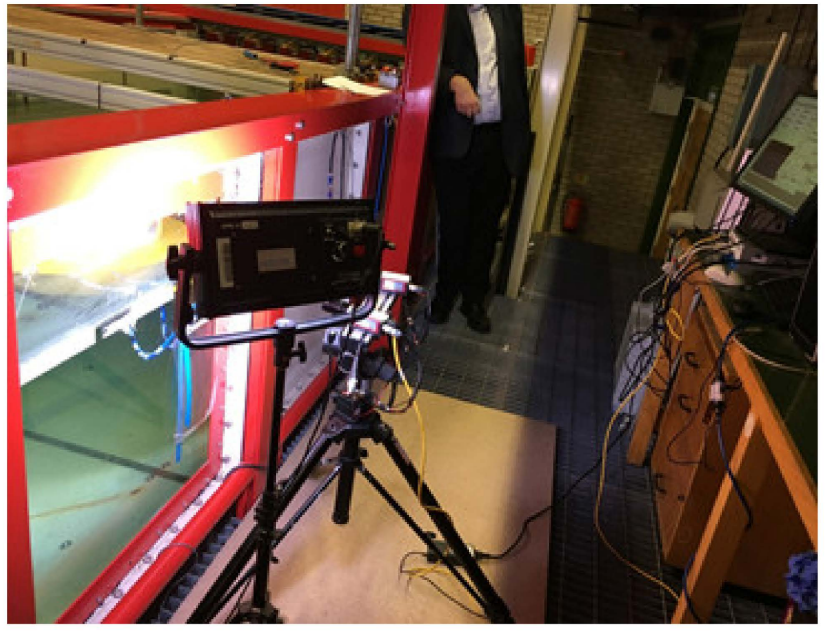

(b)

Figure 8. Experimental setup showing (a) floating hose attached on the buoy with the attached wave gauges on the buoy skirt and (b) the Imetrum system using DCI for data collection during the decay test at Lancaster University Wave Tank.

\subsection{Imetrum DIC (Digital Image Correlation) System}

The experiment was conducted using three different novel techniques, which are: a digital image capturing using Imetrum systems, using wave gauges arranged in a unique pattern and using underwater Bluetooth sensors. The Imetrum DIC system is shown in Figure 8b. The study was analysed with a digital image capturing (DIC) mechanism called the Imetrum system $[75,76]$. This system comprises two cameras and one noncontact system. It is designed for application in mechanical investigations fluid- and light wavesrelated. The Imetrum system can be used to capture both static and dynamic motions. It has been applied in capturing motion behaviour and structural investigations. Different researchers have applied the Imetrum system in obtaining results on deformation, strain, tension, compression and displacement, as well as for other material tests [77-79]. The experiment setup details are presented in Sections 2.1 and 2.2.

\subsection{Wave Gauges and Readouts}

The experiment was also conducted using some wave gauges that were calibrated with crocodile clips with the right polarity and attached to the lead ends on the model test. The maximum signal input was $5 \mathrm{~V}$ for each of the 10 wave gauges (WG0, WG1, WG2, ... WG9). This also aided the instrumentation as an interface to obtain the results. A network was developed in LabView $[80,81]$ to enable the wave gauges to communicate with the readout devices and the NI DAQ sets. The wave gauges are shown in Figure 8a, and the results obtained are presented in Section 3.

\subsection{WIT Bluetooth Gyro Underwater Motion Sensors}

Figure 9 shows the two BWT901CL WIT Motion's Bluetooth gyro sensors [82] utilised in this experiment. The devices were paired to a Samsung Galaxy 8 smartphone's mini-IMU app. The Bluetooth devices had to be charged via a USB cable system before using them. The results obtained using these devices are given in Section 3. This smartphone operates on android software, and the WitMotion sensor vendors provided the software download link [82,83]. The WitMotion WT901B sensor has a 10-Axis AHRS IMU Sensor accelerometer, gyroscope, angle measurement, magnetometer and barometer MPU9250 that works on PC, Android and MCU and, thus, was suitable for use. The Samsung Galaxy 8 is a smartphone that runs on an Android Operating System [84,85]. The smartphone was more flexible than using the laptop PC software running on the Windows Operating System. The android 
application called mini-IMU was downloaded on the phone and on the laptop PC (personal computer) running on Microsoft Windows 10.

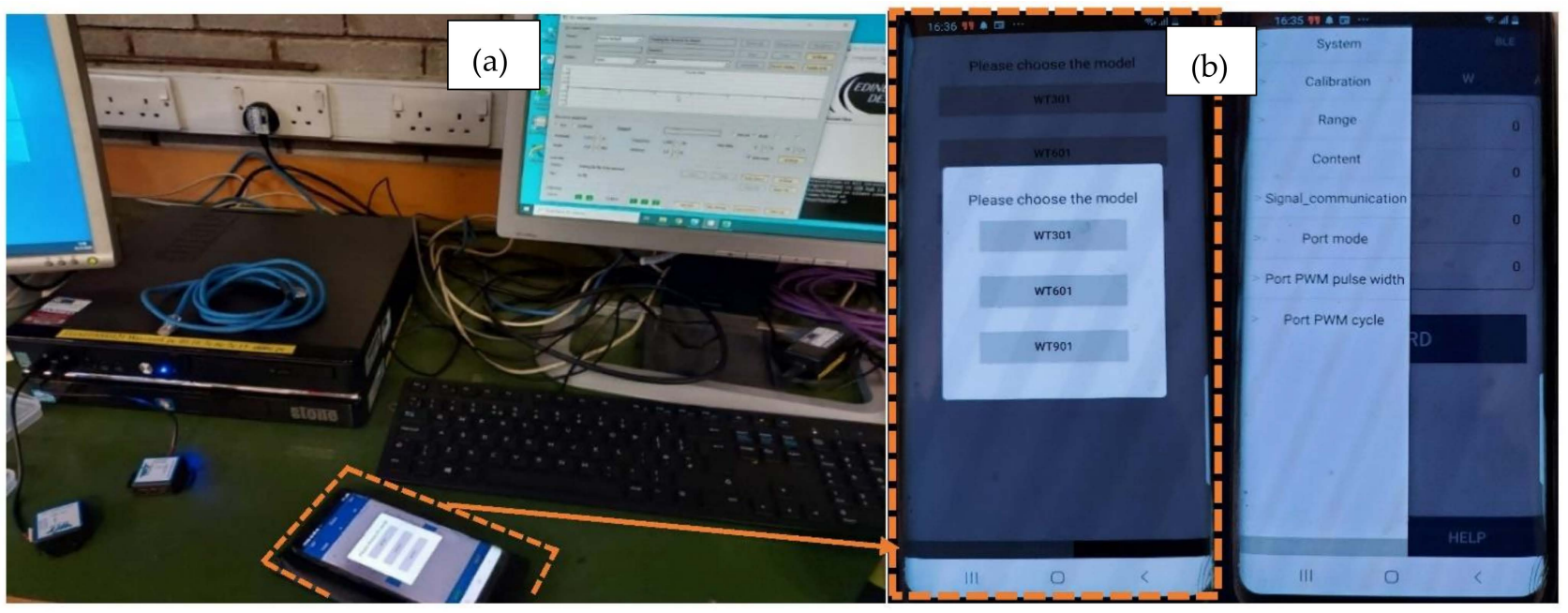

Figure 9. Experiment using 2 underwater Bluetooth WIT motion sensors paired on a Samsung Galaxy 8 smartphone, showing (a) the PC for running the wave tank calibration software and (b) the interface of the Samsung Galaxy phone displaying the WIT motion's mini-IMU app.

\subsection{Underwater $4 \mathrm{~K}$ Camera}

Two AKASO EK7000 waterproof underwater cameras with Ultra-High Definition (UHD) $4 \mathrm{~K}$ image quality with $170^{\circ}$ wide views [86] were used to record the images and videos of the experimental runs. Each camera was positioned strategically to obtain the target images and video recordings for postprocessing of the motion study with respect to the time response. The image of the AKASO camera utilised is represented in Figure 10a. The underwater views of the CALM buoy and submarine hoses are shown in Figure 10b. The reflection of the buoy skirt can be seen in Figure 10b which is an issue with a wave tank with smaller size in comparison to the size of the buoy model. To reduce the effect of this reflection, a dark surface was used on one side of the wave tank.

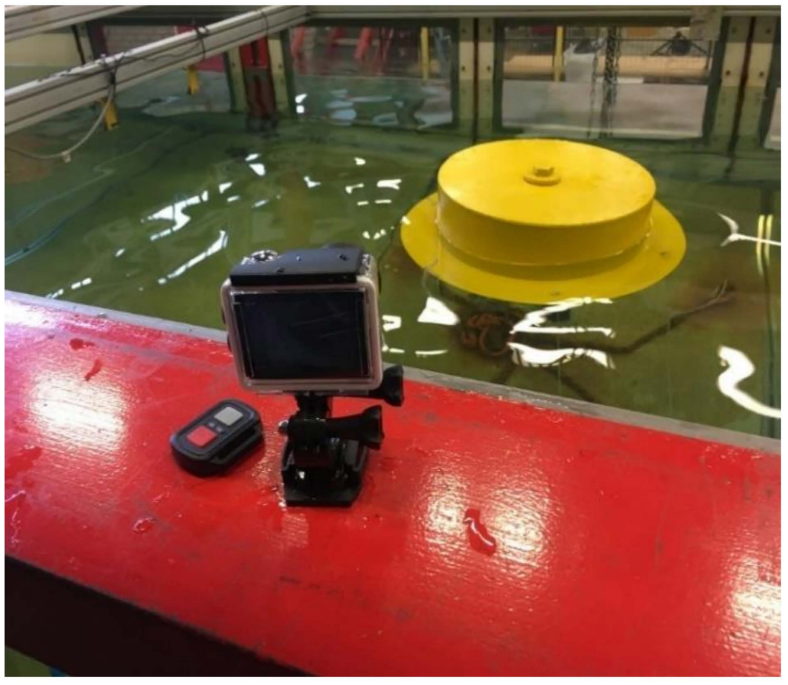

(a)

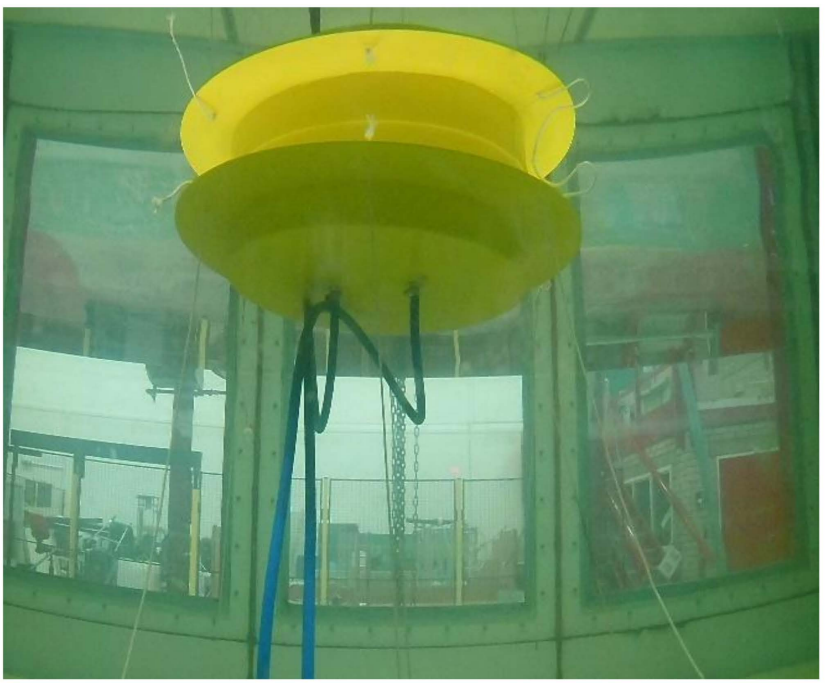

(b)

Figure 10. Setting up the CALM buoy model, showing (a) the underwater camera and top view of the buoy, and (b) underwater view of the buoy and submarine hoses (with reflection of buoy's skirt). 


\subsection{Methodology}

The experimental setup was conducted as given in Section 2.1. The methodology for the experiments was based on the phases. During this research, four different phases of the experiment were conducted. The first phase was the buoy motion study, while the second was a hose response study. The third phase was a snaking hose study, while the fourth was a reeling hose connection. The snaking hose study was investigated using the idealisation from the marine hose developments reviewed in earlier studies [28-31].

In the experimental model presented in Figures 3-6, the floating hose was attached from a CALM buoy model to an FPSO model. It can be observed that the snaking phenomenon was evident, which was due to the water waves. Additionally, the floating hose model was $20 \mathrm{~mm}$ in diameter and made of a flexible material to reflect the typical marine bonded hoses. It was attached to another FPSO model. Thus, this model was applied on the snaking hose study. The findings on the buoy motion study are detailed in Section 3. However, in the present paper, both the results of the hose snaking and the hose response studies are not included, but in another paper by the authors. The present results concentrated on the buoy motion, using the buoy attachments with hoses and the mooring lines.

\subsection{Engineering Application: Numerical Studies}

The engineering application of the modelling was carried out numerically in previous studies using the CALM buoy model in two configurations, namely the Lazy-S [87] and Chinese lantern [88] configurations. Figure 11 shows the typical numerical modelling of a CALM buoy showing two different motion positions of the buoy model in Orcaflex 11.0f. It was developed using a finite element model (FEM) in Orcina's Orcaflex as a model in the Chinese lantern configuration to confirm the engineering application, as detailed in the reference literature [89-92]. From these studies, the engineering application of the model was numerically conducted to reflect its applicability and some validity. Another application was a sea trial testing using S-lay configuration published in Wang's study [93]. In the present study, further analysis experimental studies were conducted. The recorded results were also postprocessed to confirm the consistency in the CALM buoy hose motion response, as presented in Section 3. The analysis of the results from this research are based on the experimental output. However, details were still missing when considering the hydrodynamics theory for the boundary value problem.

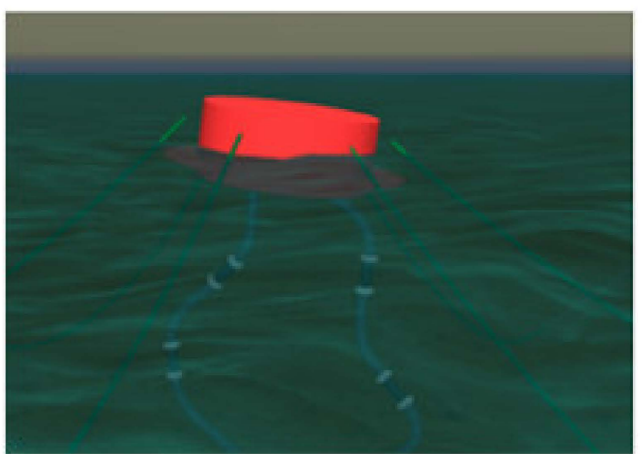

(a)

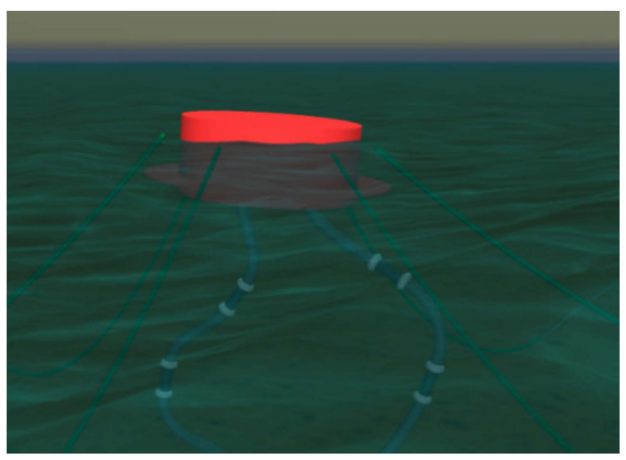

(b)

Figure 11. Numerical model of submarine hoses attached to a floating buoy in Orcaflex 11.0f, showing two different motion response positions for the CALM buoy system, in (a) position 1 at time 1 and (b) position 2 at time 2, under the same environemental conditions.

\subsection{Experimental Data Postprocessing}

The experiment conducted in the wave tank was also videoed using two AKASO EK7000 underwater action cameras with 4K HD capabilities. They were positioned at two different angles, one on the side while the other camera was underneath to obtain a video of 
the buoy and hose motions. To adequately access the motion response, some postprocessing was conducted on the recorded video output using Tracker version 6.0.2 [94-96]. From the captured responses and results in Figures 12 and 13, it can be observed that, for different profiles, the floating buoy had different responses captured per time.

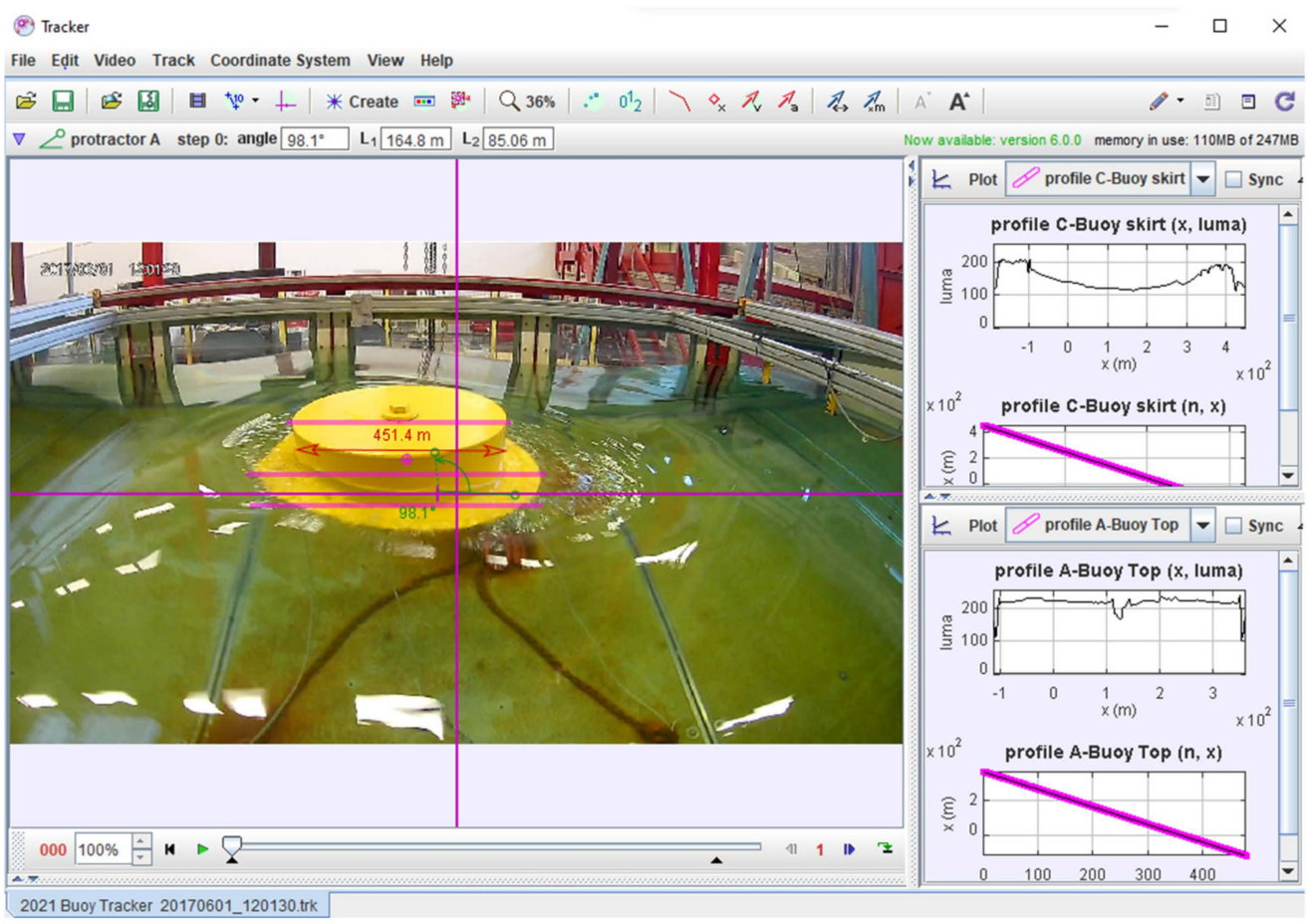

Figure 12. Resulting plots from the experiment on the model using Tracker postprocessing software, showing the profile positions.

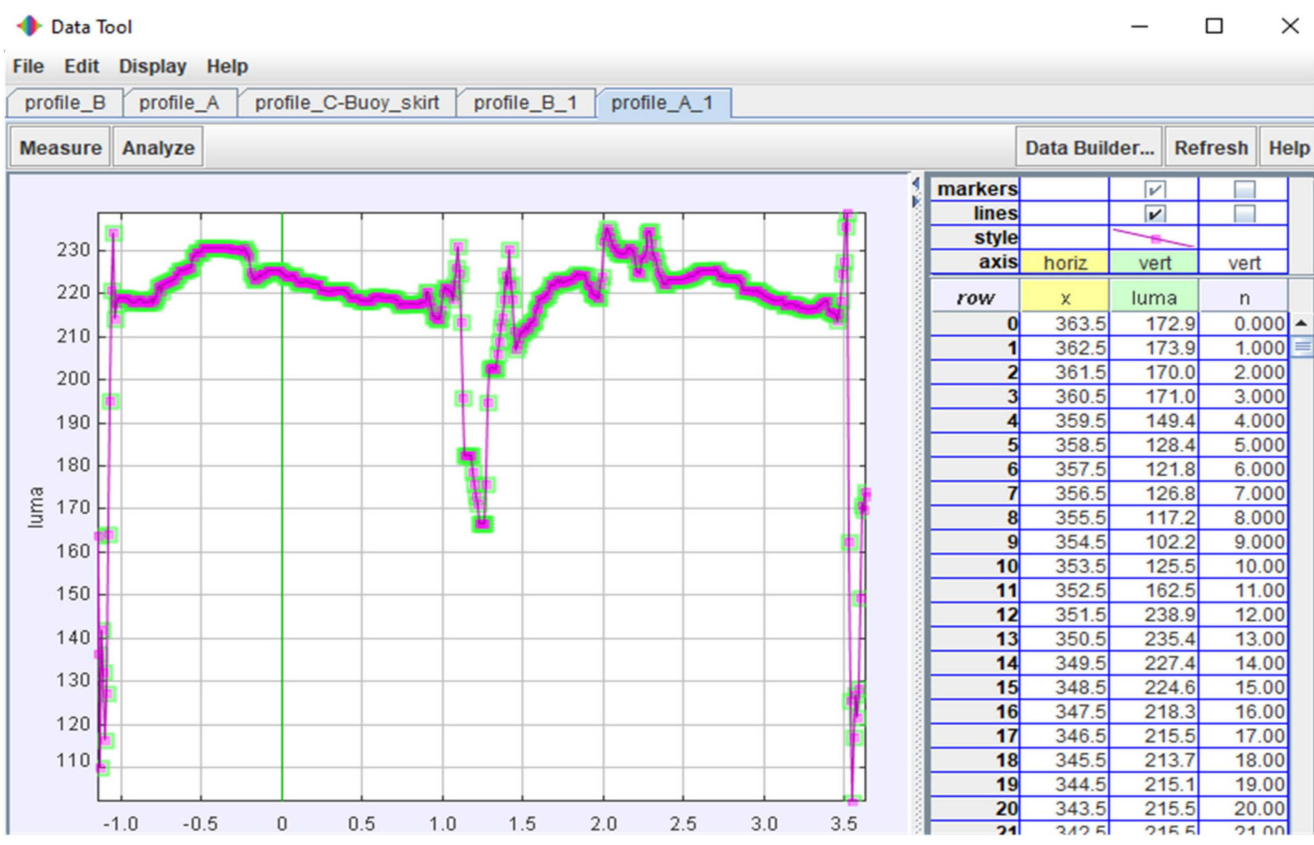

Figure 13. Analysis from the experiment using Tracker postprocessing software for profile A1.

\section{Results and Discussion}

The experimental results on the motion response of the CALM buoy with connected submarine hoses and floating hose are presented in this section. 


\subsection{Results from Wave Gauges and Readout}

The wave parameters run on the wave tank, and the experimental model is used to obtain the results on the influence of the wave angles, amplitude and frequency obtained using wave gauges, as shown in Figure 8. Figure 14 gives the waveform results obtained.
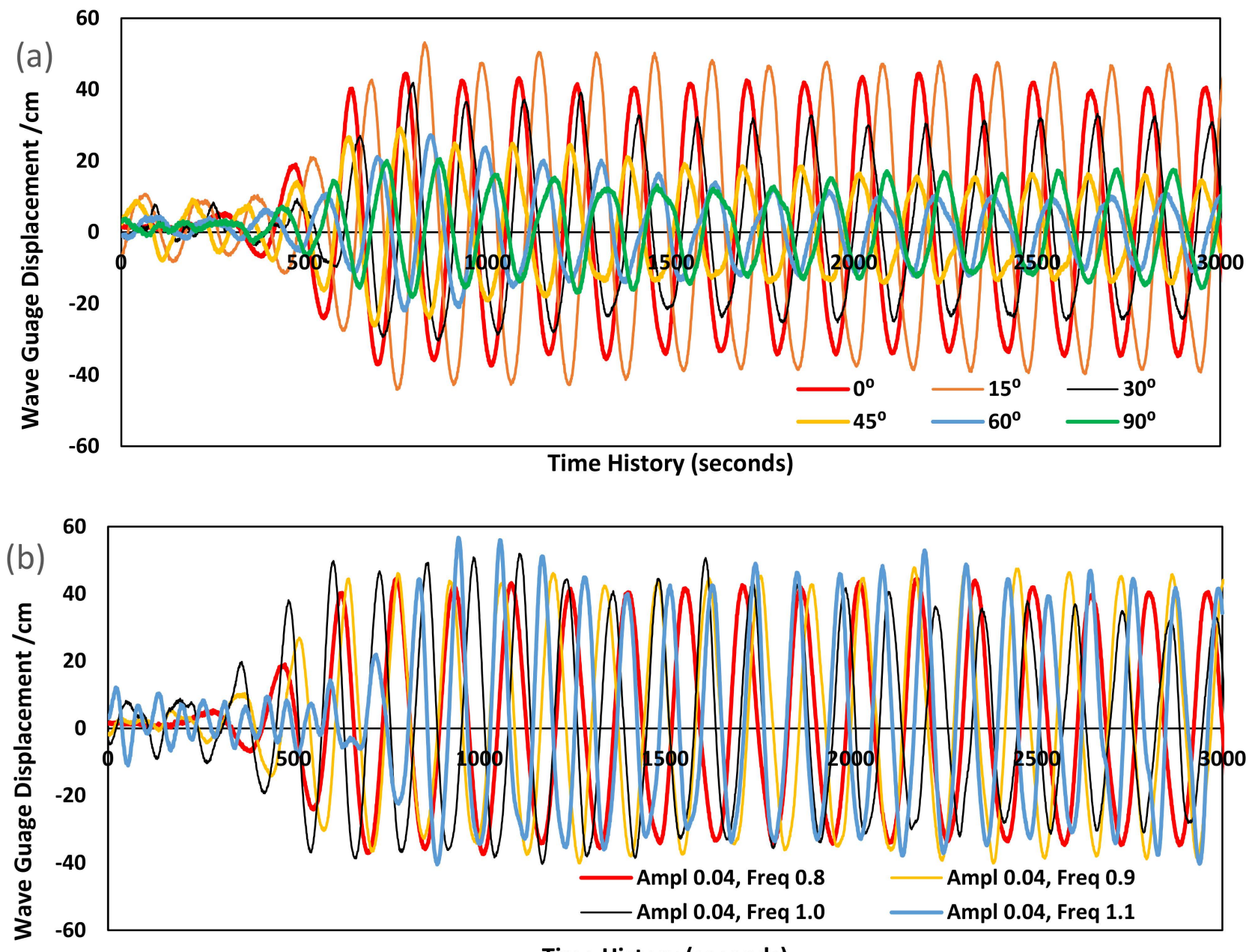

Time History (seconds)

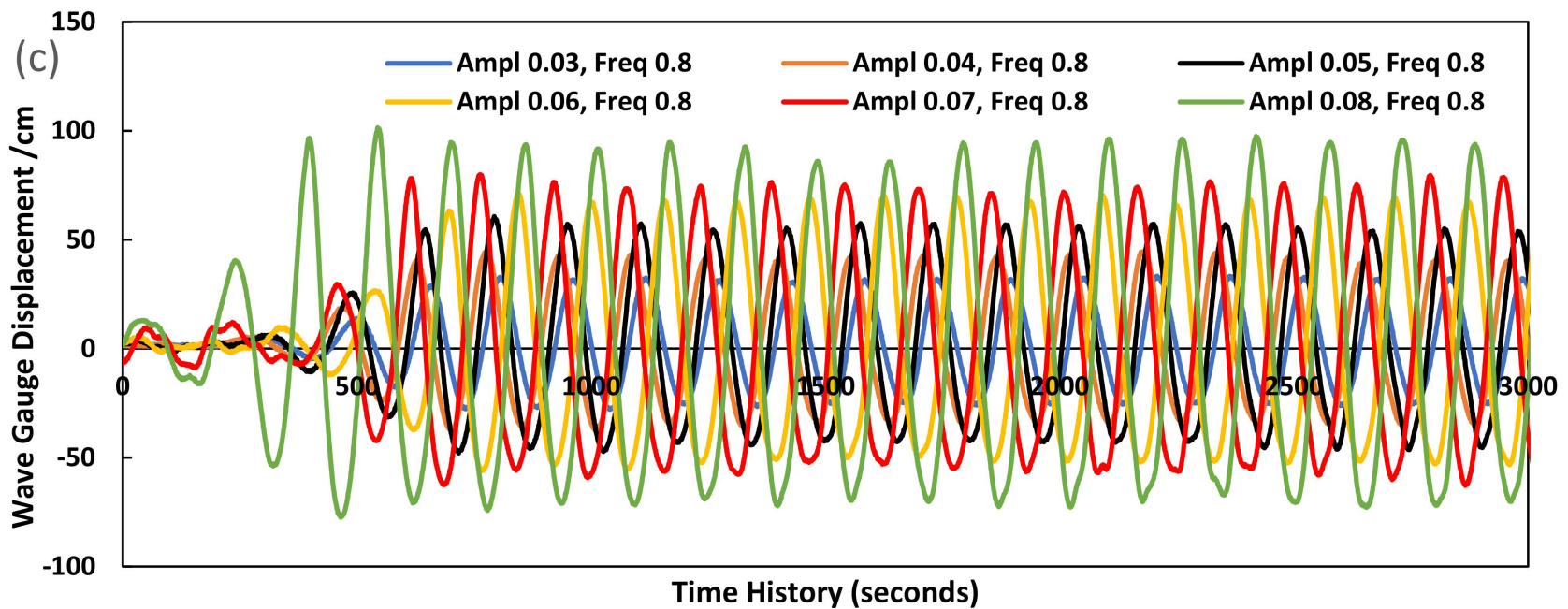

Figure 14. Results from the experiment showing the effect of (a) the wave angles, (b) frequency and (c) amplitude. 
From the results obtained on the wave forms in Figure 14a, a variation in the wave angles had varying amplitudes in the wave forms. The effect of frequency from the experiment as described was also conducted as presented in Figure 14b. Using the same amplitude of $0.04 \mathrm{~m}$, the highest frequency was $1.1 \mathrm{~Hz}$, while the lowest was $0.8 \mathrm{~Hz}$. The effect of the amplitude is seen in Figure 14c, as the higher the amplitude, the higher the wave form.

\subsection{Results from Wave Tank's Underwater Motion Sensors}

The experiment was setup as described in Section 2.8 using the Bluetooth underwater sensors paired to a Samsung Galaxy 8 smartphone, as shown in Figure 9. However, the phone was more flexible to use. The phone was paired to the Bluetooth device BWT901CL, and then, the waves were run for the desired waves, as in Tables 2 and 3 . The wave parameters run on the wave tank are presented in Table 2, as obtained using the wave tank interface in Figures 3 and 9. The results obtained are presented in this section.

From Figure 15, three equations representing the profiles on: (a) the wave frequency versus period, (b) surge response and (c) heave response were obtained as follows:

$$
\begin{gathered}
y=0.3339 x^{2}-1.4905 x+2.1487, R^{2}=0.9986 \\
y=-0.0074 x^{2}+0.0333 x-0.0208, R^{2}=0.998 \\
y=0.0618 x^{2}-0.137 x+0.077, R^{2}=0.9413
\end{gathered}
$$

However, further processing of the motion response against equations of motion was useful in obtaining the terms for the unknowns in each equation. Further hose motion response studies can be found in the literature [73,74].

In Table 2, it is noteworthy to add that these parameters were used based on the calibrations on the Lancaster University Wave Tank at a wave frequency of $1 \mathrm{~Hz}$. The wave tank has the capacity for both tidal waves and ocean waves; however, the latter was utilised in this experiment. Table 3 presents the results of the experiment using a single wave direction, and the flow was calibrated for regular waves.

Table 2. Parameters for the hydrodynamic experiment on a wave tank.

\begin{tabular}{llllll}
\hline Parameters & Amplitude & Angle & Frequency & Distance & Max Runtime \\
\hline Value & 0.078 & 0.0 & 1.0 & 5.0 & 64.0 \\
\hline Unit & $\mathrm{m}$ & Degree $\left(^{\circ}\right)$ & $\mathrm{Hz}$ & $\mathrm{m}$ & secs \\
\hline
\end{tabular}

Table 3. Results of the maximum amplitude during the experimental test.

\begin{tabular}{llll}
\hline Parameters for the Wave & Max Displacement & \\
\hline Frequency, f (Hz) & Period, $\mathbf{T}(\mathbf{s})$ & Surge $(\mathbf{m})$ & Heave (m) \\
\hline 0.5 & 2.0 & 0.01506 & 0.04660 \\
\hline 0.6 & 1.6 & 0.01301 & 0.02640 \\
\hline 0.7 & 1.4 & 0.01150 & 0.00190 \\
\hline 0.8 & 1.2 & 0.00825 & 0.00240 \\
\hline 0.9 & 1.1 & 0.00633 & 0.00260 \\
\hline 1.0 & 1.0 & 0.00465 & 0.00220 \\
\hline
\end{tabular}



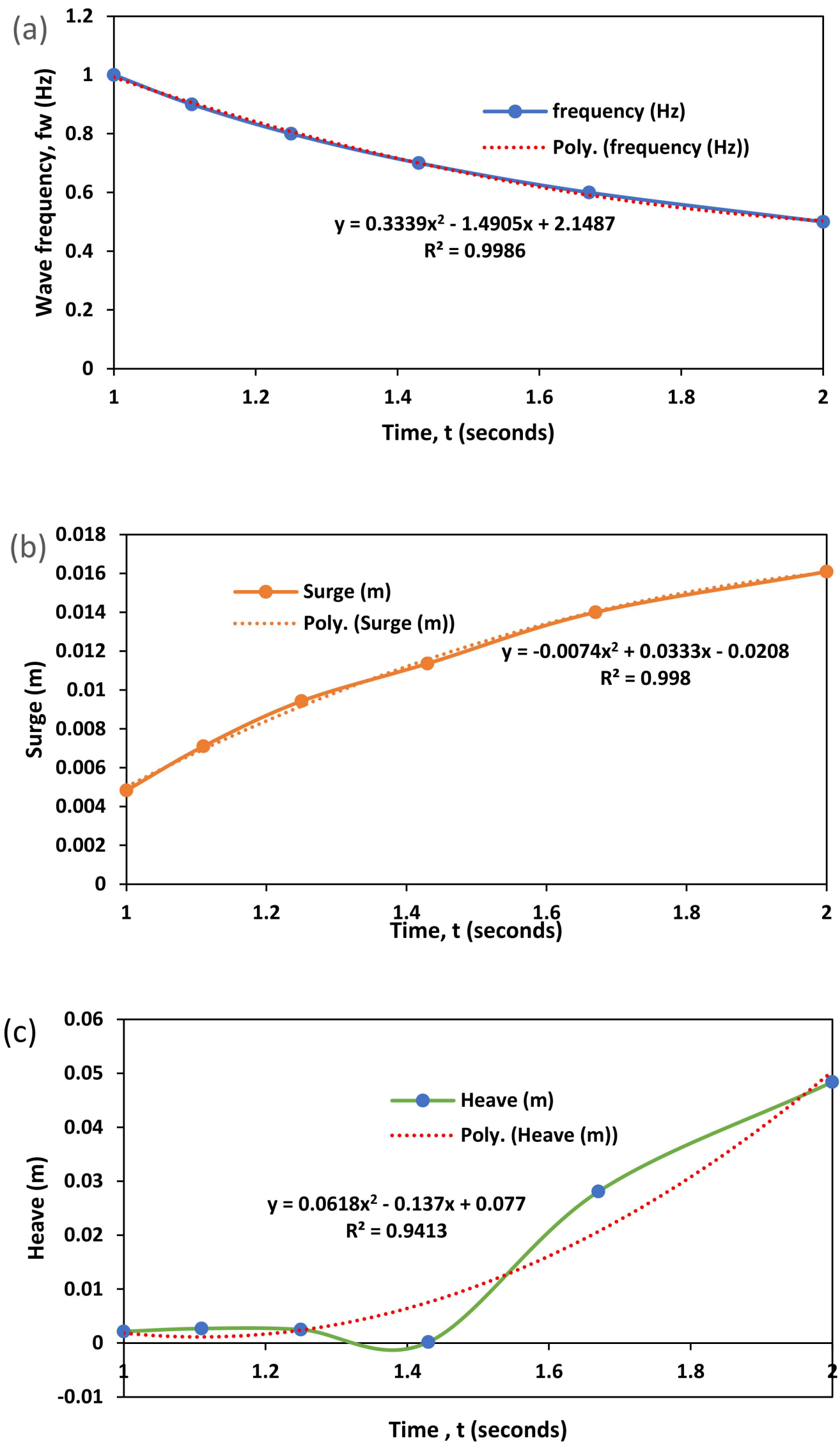

Figure 15. Result plots from the experiment on the model under the maximum displaced amplitude showing (a) the wave frequency versus period, (b) surge response and (c) heave response. 


\subsection{Results from DIC Using Imetrum System}

The experiment was set up and also carried out as described in Section 2. The wave parameters run on the wave tank are presented in Table 2, as obtained using the wave tank interface in Figures 3 and 9. Table 3 presents the results of the experiment using a single wave direction, and the flow was calibrated for regular waves. The results of the experimental model were obtained with two methods: using the wave gauges via LabView and, secondly, via the Imetrum system for the heave and surge of the CALM buoy system. The motions in the $\mathrm{X}$ and $\mathrm{Z}$ directions were studied, as defined in Figure 2. The Imetrum system was used to perform a motion study in the section based on a method called the digital image capturing (DIC) methodology. The buoy had spots marked on it that were captured during the runup and used to obtain responses against positions per time. The wave runup data in Table 3 were used to obtain the plots in Figures 16-21.

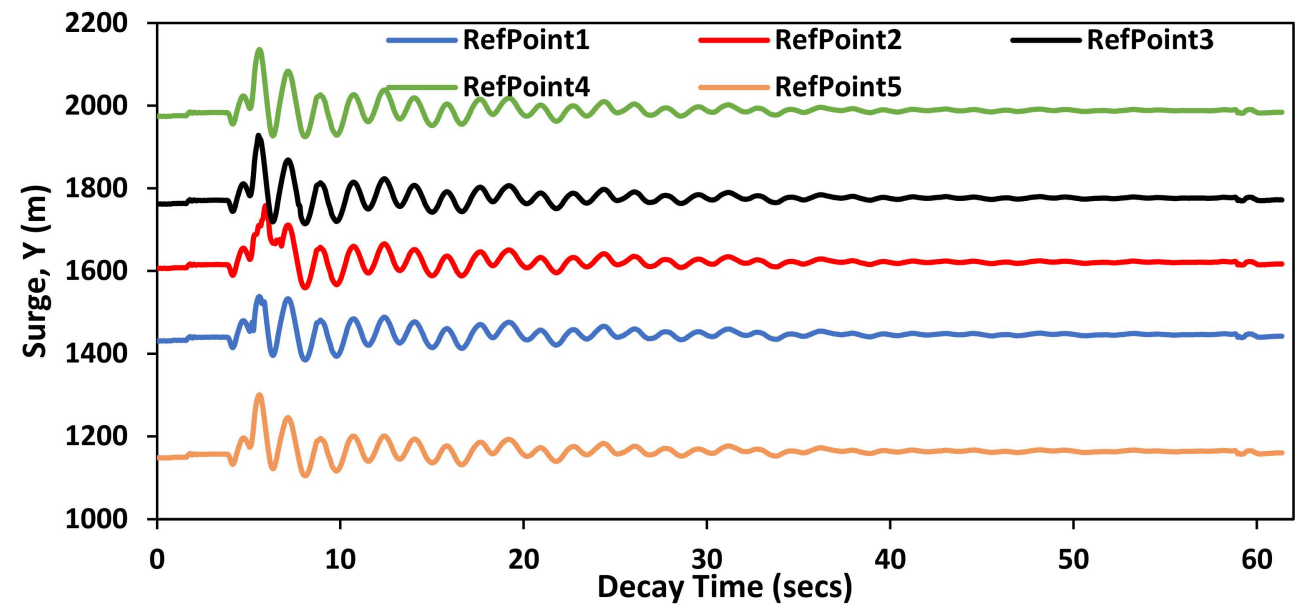

Figure 16. Surge motion for the decay test of the CALM buoy using the DIC with the Imetrum system for a 62 -s run.

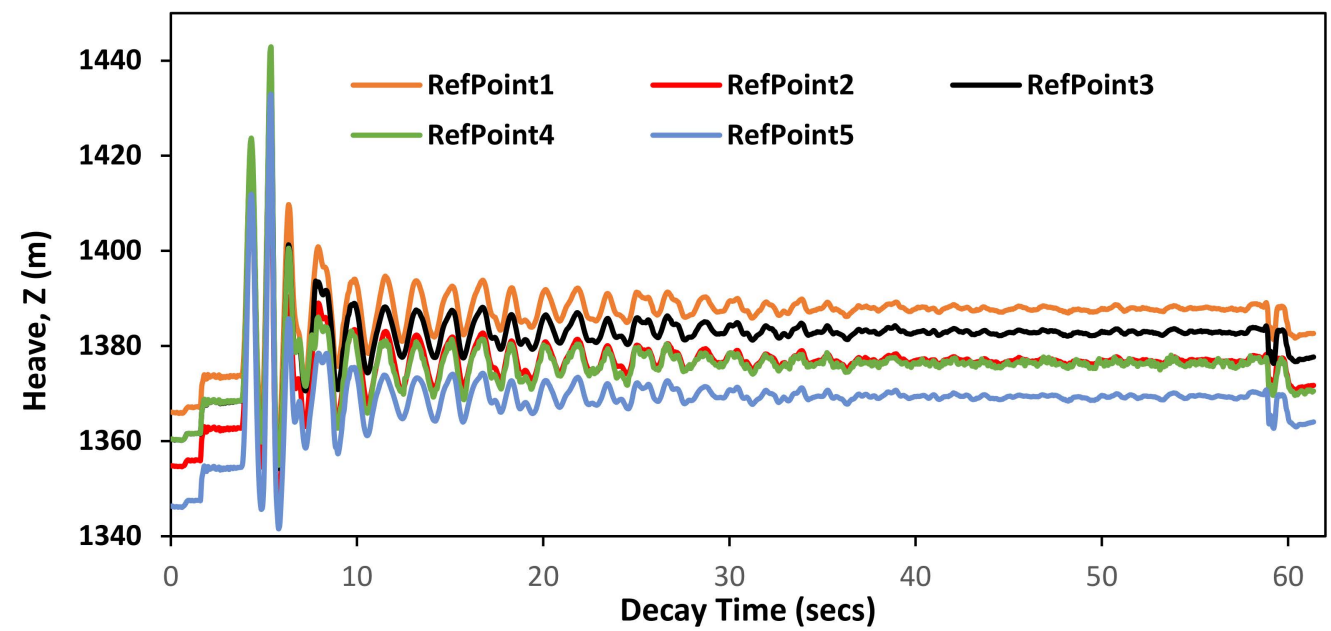

Figure 17. Heave motion for the decay test of the CALM buoy using the DIC with the Imetrum system for a $62-$ s run.

The decay tests conducted in this section show the motion response for different motion studies conducted under three different run times of $62 \mathrm{~s}$ and $80 \mathrm{~s}$. As observed in Figures 16-21, the surge response along the five (5) different reference points are consistent but show a different amplitude that is consistent, as the arrangement used was in a pattern that confirmed that the results worked well, as predicted, and a good agreement from the surge can be applied in validating similar numerical models. The first set of runs was 
undertaken in $62 \mathrm{~s}$. As recorded in the surge motion in Figure 16, the surge was the highest in reference 4 at $2117 \mathrm{~m}$ at $5.7 \mathrm{~s}$. As recorded in the heave motion in Figure 17, the heave was also consistent for the five (5) reference points obtained and was also the highest in reference 4 at $1441 \mathrm{~m}$ at $5.3 \mathrm{~s}$. As recorded in the roll motion in Figure 18, the heave was also consistent for the five (5) reference points obtained and was also the highest in reference 4 at 2.3 degrees at $5.4 \mathrm{~s}$. The next set of runs were undertaken in $82 \mathrm{~s}$. As recorded in the surge motion in Figure 19, the heave was also consistent for the five (5) reference points obtained and was also the highest in reference 4 at $2193 \mathrm{~m}$ at $2.7 \mathrm{~s}$. As recorded in the heave motion in Figure 20, the heave was also consistent for the five (5) reference points obtained and was also the highest in reference 1 at $1511 \mathrm{~m}$ at $2.2 \mathrm{~s}$. Lastly, the heave motion in Figure 20 showed that the heave was consistent for the five (5) reference points obtained and was also the highest in reference 2 at 1.5 degrees at $2.3 \mathrm{~s}$. Additionally, this confirmed the buoy response characteristics, as considered during the normal test run and the decay tests. The plots showed consistency with the lines of the best fit and the equations on these relationships. On the roll motion given in Figure 21, the five (5) reference points obtained showed a closed correlation for their responses. It could be observed that the response amplitude from the wave on the CALM buoy hoses was consistent. The motion video data from the experimental study was further postprocessed, as presented in Section 3.4.

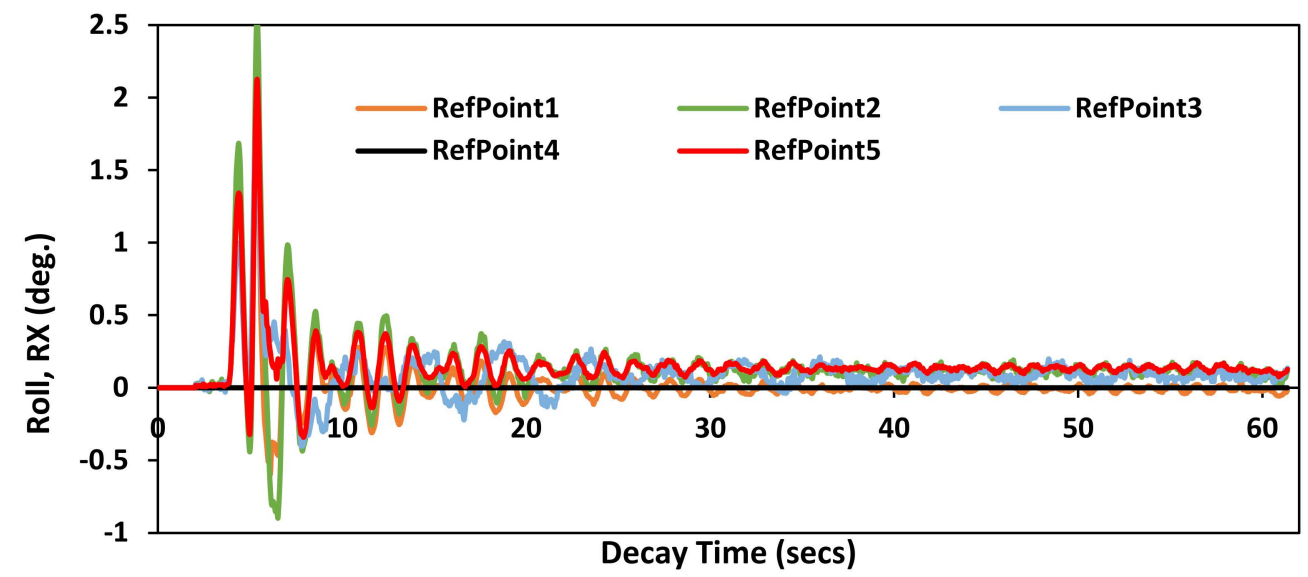

Figure 18. Roll motion for the decay test of the CALM buoy using the DIC with the Imetrum system for a 62 -s run.

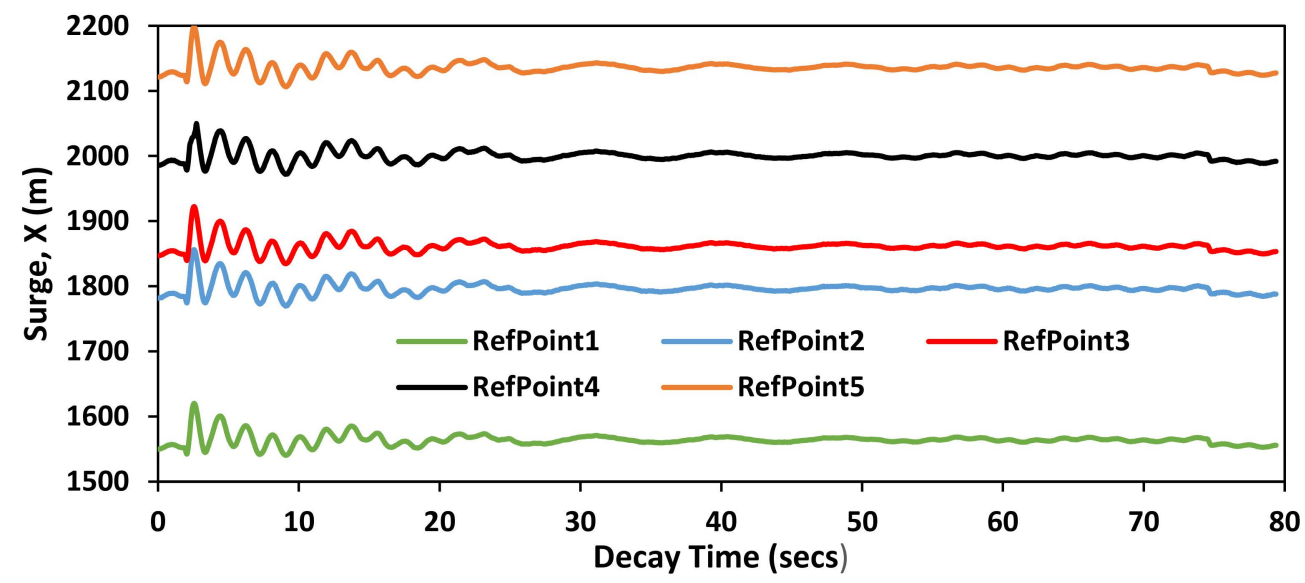

Figure 19. Surge motion for the decay test of the CALM buoy using the DIC with the Imetrum system for a 80 -s run. 


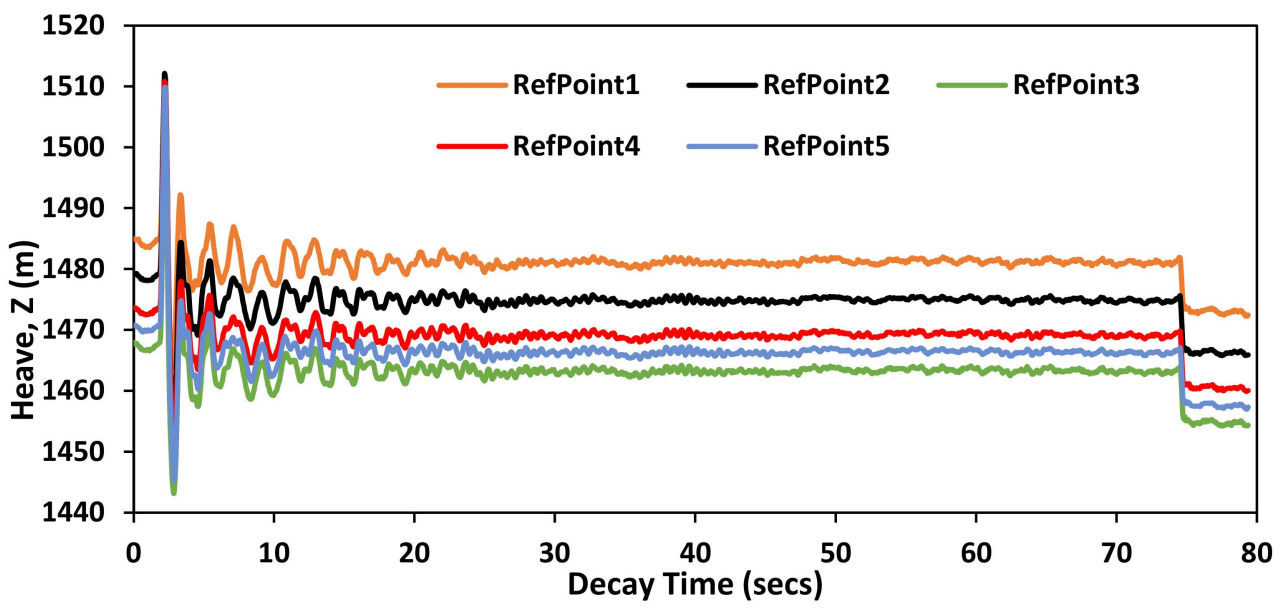

Figure 20. Heave motion for the decay test of the CALM buoy using the DIC with the Imetrum system for an 80-s run.

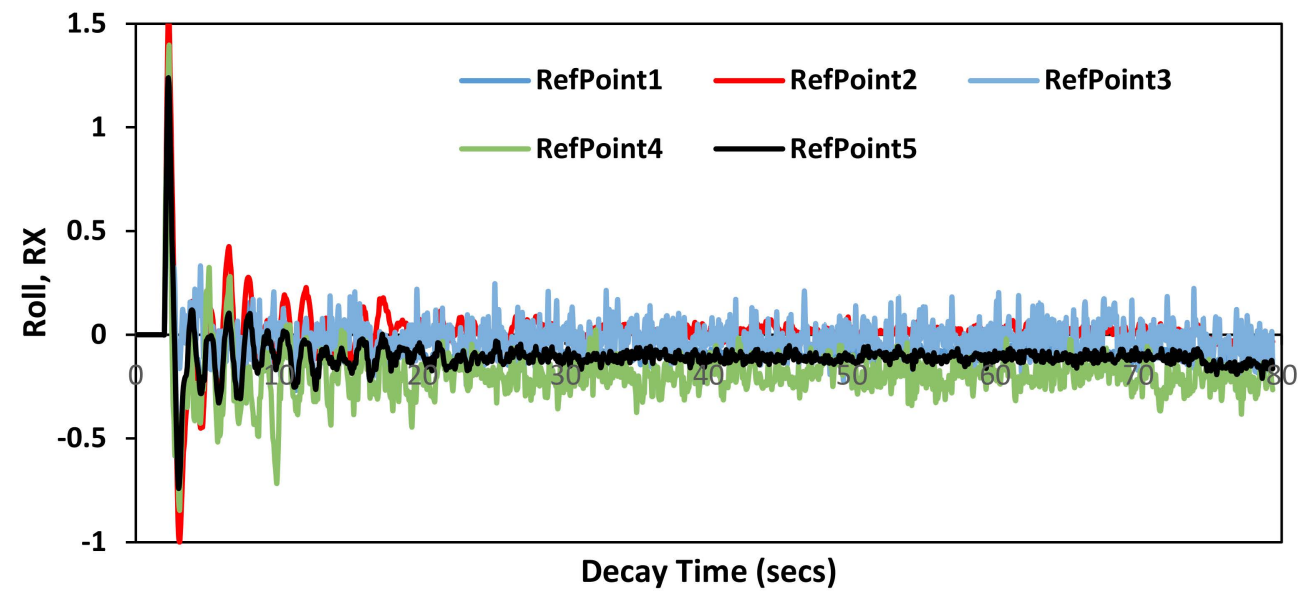

Figure 21. Roll motion for the decay test of the CALM buoy using the DIC with the Imetrum system for an 80-s run.

\subsection{Results from Tracker Postprocessing}

The recorded video from this experimental study was postprocessed, as detailed in Section 2.12. The postprocessing on the recorded output was conducted via Tracker version 6.0.2. From the captured responses and results in Figures 22 and 23, it can be observed that, for different profiles, the floating buoy has different responses captured per time. Tables 4 and 5 present the result profiles for Profiles A and B, respectively. It shows that the Luna axis increases as the baseline axis, $x$, decreases. This shows a decay rate of the motion response, as in Section 3.3. It was observed that the profiles have different sinusoidal plots on the wave response. Figures 22 and 23 give the result plots from the experiment on the buoy model under the maximum displaced amplitude. In the results in Figure 22, the wave response to the four selected profiles: A, A1, B and C are presented. It shows that each profile has a different motion response relative to the selected position of the profile based on the coordinate positions. Additionally, the result of the postprocessing in Figure 22 shows sinusoidal plots with the least trough seen as a drop within the range of $1.1 \mathrm{~m}-1.4 \mathrm{~m}$, implying that the motion response is time-dependent for a free-floating buoy. From the plot in Figure 23, it can be noticed that the rotation per time for each frame increases for the same angle when using $1.57^{\circ}$. This confirms the motion behaviour of the buoy under water waves. 


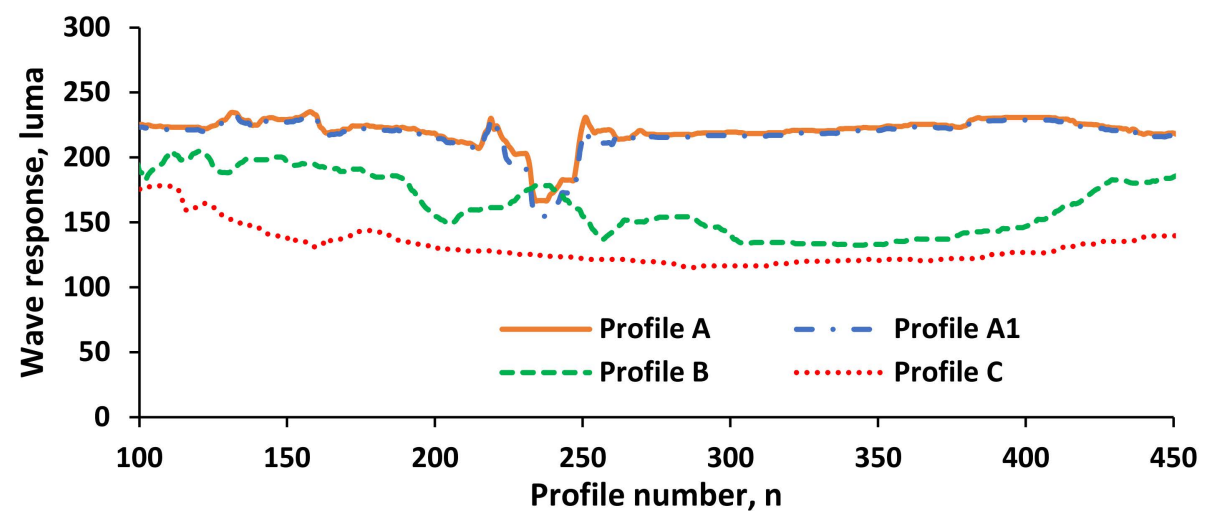

Figure 22. Result plots from the experiment for profiles A, A1, B and C.

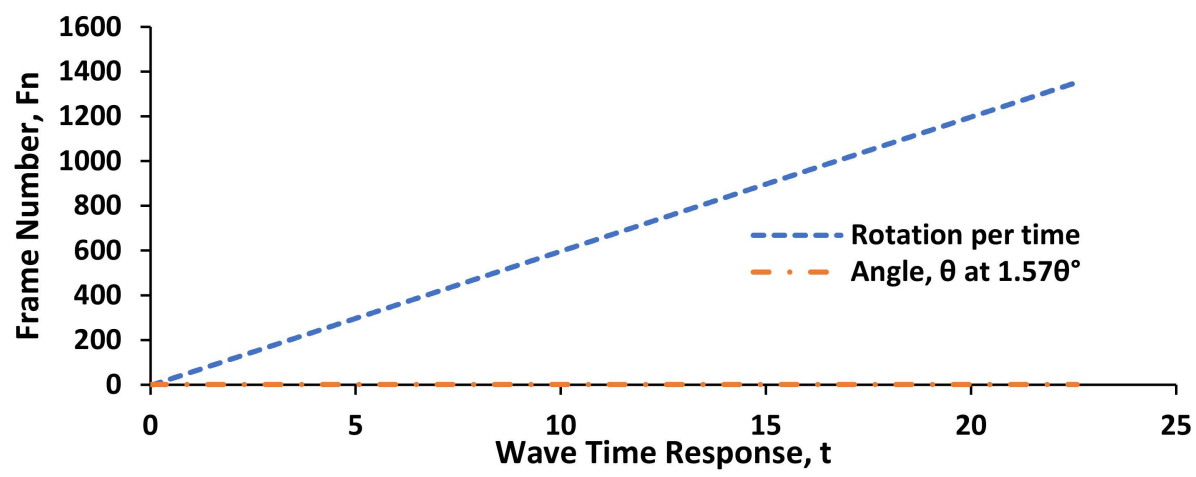

Figure 23. Plot from the experiment per frame increment for the same angle using $1.57^{\circ}$.

Table 4. Data analysis from the experiment using Tracker postprocessing software for Profile A.

\begin{tabular}{lll}
\hline Horizontal, $\boldsymbol{n}$ & Vertical, $\mathbf{x}$ & Vertical, Luna \\
\hline 0 & 363.5 & 172.9 \\
1 & 362.5 & 173.9 \\
2 & 361.5 & 170.0 \\
3 & 360.5 & 171.0 \\
4 & 359.5 & 149.4 \\
5 & 358.5 & 128.4 \\
6 & 357.5 & 121.8 \\
7 & 356.5 & 126.8 \\
8 & 355.5 & 117.2 \\
9 & 354.5 & 102.2 \\
10 & 353.5 & 125.5 \\
11 & 352.5 & 162.5 \\
12 & 351.5 & 238.9 \\
13 & 350.5 & 235.4 \\
14 & 349.5 & 227.4 \\
15 & 348.5 & 224.6 \\
16 & 347.5 & 218.3 \\
17 & 346.5 & 215.5 \\
18 & 345.5 & 213.7 \\
19 & 344.5 & 215.1 \\
20 & 343.5 & 215.5 \\
21 & 342.5 & 215.6 \\
22 & 341.5 & 212.8 \\
\hline
\end{tabular}


Table 5. Data Analysis from the experiment using Tracker postprocessing software for Profile B.

\begin{tabular}{lll}
\hline Horizontal, $\boldsymbol{n}$ & Vertical, $\mathbf{x}$ & Vertical, Luna \\
\hline 0 & 441.5 & 239.2 \\
1 & 440.5 & 250.3 \\
2 & 439.5 & 250.0 \\
3 & 438.5 & 245.2 \\
4 & 437.5 & 238.6 \\
5 & 436.5 & 235.6 \\
6 & 435.5 & 227.6 \\
7 & 434.5 & 220.6 \\
8 & 433.5 & 214.6 \\
9 & 432.5 & 212.6 \\
10 & 431.5 & 206.4 \\
11 & 430.5 & 203.4 \\
12 & 429.5 & 201.4 \\
13 & 428.5 & 199.4 \\
14 & 427.5 & 199.6 \\
15 & 426.5 & 199.6 \\
16 & 425.5 & 192.5 \\
17 & 424.5 & 188.5 \\
18 & 423.5 & 180.4 \\
19 & 422.5 & 180.4 \\
20 & 421.5 & 175.6 \\
21 & 420.5 & 179.6 \\
22 & 419.5 & 184.9 \\
\hline
\end{tabular}

\subsection{Discussion}

The motion characteristics of a CALM buoy hull structure have been studied experimentally. Figure 13 gives the result plots from the experiment on the buoy model under the maximum displaced amplitude, showing (a) the wave frequency versus period, (b) surge response and (c) heave response. Decay tests were also conducted in Section 3.3. It showed the motion response for different motions conducted under two different run times of $62 \mathrm{~s}$ and $80 \mathrm{~s}$. From the results presented in Figures 16-21, it could be observed that the motion behaviour of the CALM buoy hose system was recorded from the experiment. In the results in Figure 22, the wave response to the four selected profiles: A, A1, B and $\mathrm{C}$ are presented. It was observed that the profiles had different sinusoidal plots on the wave response. However, further study on the research is recommended to look at two forms of motion analysis: vortex-induced motion, which is caused by resonance from reciprocating shed vortexes, and wave-induced motion, which is caused by the dynamism of the wave characteristics. The wave-current interactions and wave-induced motion have been conducted experimentally. In this research, the motions caused by the hydrodynamic loads were studied at the wave tank facility of Lancaster University. Since the buoy had a smaller reciprocating amplitude than larger floating structures like semisubmersibles, it can be assumed that it had a better vortex-induced motion (VIM) response. This could be due to a number of factors, including the geometric features of the buoy's diameter, the geometric shape and the skirt positioning and mooring configurations. Under regular waves, the wave-produced motions showed a modest response, and the heave motion was found to be inversely proportional to the draught size. It is crucial to note that the results obtained from the Lancaster University Wave Tank facility were used for the experiment. The study results could be used for validation purposes in further studies. It can be observed in the results in this section that the buoy motion changes the behaviours relative to the water waves on both the buoy and the hoses.

The motion video data from the experimental study was further postprocessed. This motion postprocessing shows that the responses are consistent on different profiles for the hydrodynamic phenomenon, particularly from the high surge response. For the results from Section 3.4, it could be observed that the surge and heave motions increased as 
the time increased. Additionally, this confirmed the buoy response characteristics, as considered during the normal test run and the decay tests. The plots showed consistency with the lines of best fit and the equations on these relationships. From the postprocessing results using Tracker software, some tables were generated and used to create plots of the profile response per time. This showed stable behaviour of the floating buoy under the time investigated. This study can be further developed by using some comprehensive formulations of the buoy for more understanding on the stability and dynamics behaviours of floating buoys.

\section{Concluding Remarks}

In this research, an experimental study on the motion characterisations of a CALM buoy under water waves was investigated. Some background on the experimental model for the CALM buoy system was presented in Section 2. However, special attention was given to the CALM buoy and the skirt. The results showed peculiar characteristics that should be considered in the design due to the drag and damping implications. The results of the experiment were presented on the motion characterisation study. Some discussions were included on the engineering application of the system with numerical computations in earlier studies. This study is relevant for enabling engineers to appropriately design CALM buoy systems using parametric information on hose behaviour, buoy motion, buoy geometry, oceanic data and other environmental conditions.

The model highlights included the following: firstly, an experimental framework was presented on motion characterisation for the CALM buoy model. Secondly, there was a well-detailed experimental presentation on the CALM buoy hose model conducted at the Lancaster University Wave Tank facility. Thirdly, three different novel techniques were presented, which were: a digital image capturing using the Imetrum system using wave gauges arranged in a unique pattern, using AKASO underwater 4K UHD action camera and using WitMotion underwater Bluetooth sensors. Fourthly, there was an experimental study on the motion scenario from the motion response study on wave angles and wave amplitudes from the CALM buoy hoses. Lastly, a prediction of the CALM buoy's motion characteristics was presented from the study from postprocessing using Tracker software.

The study presented response profiles based on the experimental predictions. From an offshore mechanical point of view, the motion characterisation phenomenon was confirmed to exist as a result of the response from the water waves and other global loads on the CALM buoy. The study showed more dimensions of the CALM buoy in a water body and buoy motion of the marine hose. The study also showed the wave forces acting on the CALM buoy model. This has been confirmed with previous studies by the authors using the diffraction and potential theories. Thus, this study will assist in both the manufacturing and installation of CALM buoys. The buoy model was also found to respond uniquely to each motion investigated under water waves. The results showed that the higher the profile, the higher the response of the buoy. Thus, this study confirmed the existence of flow patterns on the CALM buoy while floating on the water body. Further study is recommended with engineering application on marine hoses using the Orcaflex FEM, which could be experimentally validated. Other studies include the numerical fluid study or vortex flow effect on the buoy using CFD.

Author Contributions: Conceptualisation, C.V.A. and J.Y.; methodology, C.V.A., F.W. and J.Y.; software, C.V.A. and J.Y.; validation, C.V.A., F.W. and J.Y.; formal analysis, C.V.A. and J.Y.; investigation, C.V.A., F.W. and J.Y.; resources, C.V.A.; data curation, C.V.A.; writing-original draft preparation, C.V.A.; writing-review and editing, C.V.A., F.W. and J.Y.; visualisation, C.V.A.; supervision, C.V.A., F.W. and J.Y.; project administration, C.V.A. and J.Y. and funding acquisition, C.V.A. and J.Y. All authors have read and agreed to the published version of the manuscript.

Funding: The Department of Engineering, Lancaster University, UK and Engineering and Physical Sciences Research Council (EPSRC)'s Doctoral Training Centre (DTC) are highly appreciated. Also, the funding of the Overseas Postgraduate Scholarship by the Niger Delta Development Commission (NDDC), Port Harcourt, Nigeria is also appreciated, as well as the support of the Standards Organisa- 
tion of Nigeria (SON), F.C.T. Abuja, Nigeria. The research reported in this paper is part of Project 51922064 supported by the National Natural Science Foundation of China (NSFC), China. The article processing charges (APC) were funded by Author 1-C.V.A. with support from MDPI's JMSE.

Institutional Review Board Statement: Not applicable.

Informed Consent Statement: Not applicable.

Data Availability Statement: The raw/processed data required to reproduce these findings cannot be shared at this time, as the data also forms part of an ongoing study.

Acknowledgments: The authors acknowledge the technical support from the Lancaster University Engineering Department staff. The authors acknowledge the technical support of Mark Salisbury, Andy Baker and Nick Renninson for support on the experiments done on the CALM buoy model fabrications. The authors recognise the support from Simon Doyle of Lancaster University, UK for technical support during the experimental investigation of the model and the project contributions of Stephen Quayle of Lancaster University, who contributed to the development of the model test. The authors also acknowledge Richard Leeuwenburgh of Bluewater for permission to use their images, including Figure 1. The authors also acknowledge the feedback given on this submission by Professors George Aggidis of Lancaster University, UK and Long-Yuan Li of Plymouth University, UK. The authors are posthumously grateful to the late Jeevan Mahadev Rao of Lancaster University, who assisted with the experimental investigation of this project but unfortunately passed away during the COVID-19 pandemic after some health challenges. The authors also appreciate the editors of JMSE and the anonymous reviewers for their feedback on this submission, which have helped to improve the quality of this manuscript.

Conflicts of Interest: The authors declare no conflict of interest. The funders had no role in the design of the study; in the collection, analyses or interpretation of the data; in the writing of the manuscript or in the decision to publish the results.

\begin{tabular}{ll} 
Abbreviations & \\
$\theta$ & Angle to the Horizontal Axis \\
3D & Three-Dimensional \\
6DoF & Six Degrees of Freedom \\
ABS & American Bureau of Shipping \\
ASPM & Articulated Single Point Moorings \\
BEM & Boundary Element Method \\
CALM & Catenary Anchor Leg Mooring \\
CB & Cylindrical Buoy \\
CCS & Cartesian Coordinate System \\
CFD & Computational Fluid Dynamics \\
CMS & Conventional Mooring Systems \\
DIC & Digital Image Correlation \\
DNVGL & Det Norkse Veritas \& Germanischer Lloyd \\
F.C.T & Federal Capital Territory \\
FEM & Finite Element Model \\
FOS & Floating Offshore Structure \\
FPSO & Floating Production Storage and Offloading \\
FSO & Floating Storage and Offloading \\
GMPHOM & Guide to Manufacturing and Purchasing Hoses for Offshore \\
ID & Moorings \\
IEFG & Inner Diameter \\
MSL & Interpolating Element Free Galerkin \\
OCIMF & Mean Sea Level \\
OD & Oil Companies International Marine Forum \\
RAO & Outer Diameter \\
& Response Amplitude Operator \\
\hline
\end{tabular}




$\begin{array}{ll}\text { SALM } & \text { Single Anchor Leg Moorings } \\ \text { SON } & \text { Standards Organisation of Nigeria } \\ \text { SPM } & \text { Single-Point Mooring } \\ \text { UHD } & \text { Ultra-High Definition } \\ \text { U.K } & \text { United Kingdom } \\ \text { VIM } & \text { Vortex-Induced Motion }\end{array}$

\section{References}

1. Islam, A.S.M.S.; Jameel, M.; Jumaat, M.Z.; Shirazi, S.; Salman, F.A. Review of offshore energy in Malaysia and floating Spar platform for sustainable exploration. Renew. Sustain. Energy Rev. 2012, 16, 6268-6284. [CrossRef]

2. Sadeghi, K. An Overview of Design, Analysis, Construction and Installation of Offshore Petroleum Platforms Suitable for Cyprus Oil/Gas Fields. GAU J. Soc. Appl. Sci. 2007, 2, 1-16. Available online: https://cemtelecoms.iqpc.co.uk/media/6514/786.pdf (accessed on 6 January 2022).

3. Amaechi, C.V.; Ye, J. A review of state-of-the-art and meta-science analysis on composite risers for deep seas. Ocean Eng. 2022. under review.

4. Odijie, A.C.; Wang, F.; Ye, J. A review of floating semisubmersible hull systems: Column stabilized unit. Ocean. Eng. 2017, 144, 191-202. [CrossRef]

5. Yu, L.C.; King, L.S.; Hoon, A.T.C.; Yean, P.C.C. A Review Study of Oil and Gas Facilities for Fixed and Floating Offshore Platforms. Res. J. Appl. Sci. Eng. Technol. 2015, 10, 672-679. [CrossRef]

6. Hirdaris, S.E.; Bai, W.; Dessi, D.; Ergin, A.; Gu, X.; Hermundstad, O.A.; Huijsmans, R.; Iijima, K.; Nielsen, U.; Parunov, J.; et al Loads for use in the design of ships and offshore structures. Ocean Eng. 2014, 78, 131-174. [CrossRef]

7. Sorensen, R.M. Basic Coastal Engineering, 3rd ed.; Springer: New York, NY, USA, 2006.

8. Sorensen, R.M. Basic Wave Mechanics: For Coastal and Ocean Engineers; John Wiley and Sons: Hoboken, NJ, USA, 1993.

9. Amaechi, C.V.; Wang, F.; Odijie, A.C.; Ye, J. Numerical investigation on mooring line configurations of a Paired Column Semisubmersible for its global performance in deep water condition. Ocean. Eng. 2022. [CrossRef]

10. Boccotti, P. Chapter 11 Analysis of The Wave Forces on Offshore Structures. In Wave Mechanics for Ocean Engineering, 1st ed.; Elsevier Oceanography Series; Elsevier Science Publishers: London, UK, 2000; Volume 64, pp. 361-392. [CrossRef]

11. Boccotti, P. Wave Mechanics and Wave Loads on Marine Structures, 1st ed.; Elsevier Science Publishers, Imprint of ButterworthHeinemann Inc.: Woburn, MA, USA, 2015. [CrossRef]

12. Dean, R.G.; Dalrymple, R.A. Water Wave Mechanics for Engineers and Scientists; Advanced Series on Ocean Engineering; World Scientific Publishers: Toh Tuck Link, Singapore, 1991; Volume 2. [CrossRef]

13. McCormick, M.E. Ocean Engineering Mechanics: With Applications; Cambridge University Press: Cambridge, UK, 2010.

14. Amaechi, C.V.; Gillett, N.; Odijie, A.C.; Hou, X.; Ye, J. Composite risers for deep waters using a numerical modelling approach. Compos. Struct. 2019, 210, 486-499. [CrossRef]

15. Amaechi, C.V.; Ye, J. Local tailored design of deep water composite risers subjected to burst, collapse and tension loads. Ocean. Eng. 2022. [CrossRef]

16. Amaechi, C.V.; Ye, J. A numerical modeling approach to composite risers for deep waters. In Proceedings of the International Conference on Composite Structures (ICCS20) Proceedings, Paris, France, 4-7 September 2017; Società Editrice Esculapio: Bologna, Italy, 2017.

17. Amaechi, C.V.; Gillett, N.; Odijie, A.C.; Wang, F.; Hou, X.; Ye, J. Local and Global Design of Composite Risers on Truss SPAR Platform in Deep waters. In Proceedings of the 5th International Conference on Mechanics of Composites, Instituto Superior de Tecnico, Lisbon, Portugal, 1-4 July 2019; Volume 20005, pp. 1-3.

18. Amaechi, C.V.; Gillet, N.; Ye, J. Tailoring the local design of deep water composite risers to minimise structural weight. J. Compos. Sci. 2022, 6. under review.

19. Sun, L.; Zhang, X.; Kang, Y.; Chai, S. Motion Response Analysis of FPSO's CALM Buoy Offloading System. In Proceedings of the ASME 2015 34th International Conference on Ocean, Offshore and Arctic Engineering, St. John's, NL, Canada, 31 May-5 June 2015; Volume 11, p. V011T12A008. [CrossRef]

20. Amaechi, C.V. Novel Design, Hydrodynamics and Mechanics of Marine Hoses in Oil/Gas Applications. Ph.D. Thesis, Lancaster University, Engineering Department, Lancaster, UK, 2022.

21. Kang, Y.; Sun, L.; Kang, Z.; Chai, S. Coupled Analysis of FPSO and CALM Buoy Offloading System in West Africa. In Proceedings of the ASME 2014 33rd International Conference on Ocean, Offshore and Arctic Engineering, San Francisco, CA, USA, 8-13 June 2014; Volume 8A, p. V08AT06A010. [CrossRef]

22. Qi, X.; Chen, Y.; Yuan, Q.; Xu, G.; Huang, K. CALM Buoy and Fluid Transfer System Study. In Proceedings of the 27th International Offshore and Polar Engineering Conference, San Francisco, CA, USA, 25-30 June 2017; ISOPE: Lisbon, Portugal, 2017 ; pp. 128-932. Available online: https:/ / onepetro.org/ISOPEIOPEC/proceedings-abstract/ISOPE17/All-ISOPE17/ISOPE-I-17-128/17225 (accessed on 13 November 2021).

23. Wang, H.; Ma, G.; Sun, L.; Hu, K. Model test and coupled dynamic analysis of a deepwater FPSO with internal turret mooring system. Brodogradnja 2017, 68, 42-55. [CrossRef] 
24. Gu, H.; Chen, H.-C.; Zhao, L. Coupled CFD-FEM simulation of hydrodynamic responses of a CALM buoy. Ocean. Syst. Eng. 2019, 9, 21-42. [CrossRef]

25. Gu, H. Coupled Mooring Analysis of a CALM Buoy by a CFD Approach. Master's Thesis, Texas A\&M University, Texas, TX, USA, 2016.

26. Gu, H.; Chen, H.-C.; Zhao, L. Coupled Mooring Analysis of a CALM Buoy by a CFD Approach. In Proceedings of the 27th International Ocean and Polar Engineering Conference, San Francisco, CA, USA, 25-30 June 2017; Paper Number: ISOPE-I-17-223. Available online: https://www.researchgate.net/publication/320044188_Coupled_Mooring_Analysis_of_a_CALM_Buoy_by_ a_CFD_Approach (accessed on 23 January 2022).

27. Amaechi, C.V.; Chesterton, C.; Butler, H.O.; Gu, Z.; Odijie, A.C.; Wang, F.; Hou, X.; Ye, J. Finite Element Model on the mechanical behaviour of Marine Bonded Composite Hose under internal pressure and external pressure. J. Mar. Sci. Eng. 2022, $10,151$. [CrossRef]

28. Amaechi, C.V.; Wang, F.; Ja'e, I.A.; Aboshio, A.; Odijie, A.C.; Ye, J. A literature review on the technologies of bonded hoses for marine applications. Ships Offshore Struct. 2022. [CrossRef]

29. Amaechi, C.V.; Chesterton, C.; Butler, H.O.; Wang, F.; Ye, J. An Overview on Bonded Marine Hoses for sustainable fluid transfer and (un)loading operations via Floating Offshore Structures (FOS). J. Mar. Sci. Eng. 2021, 9, 1236. [CrossRef]

30. Amaechi, C.V.; Chesterton, C.; Butler, H.O.; Wang, F.; Ye, J. Review on the design and mechanics of bonded marine hoses for Catenary Anchor Leg Mooring (CALM) buoys. Ocean Eng. 2021, 242, 110062. [CrossRef]

31. Amaechi, C.V.; Wang, F.; Ye, J. Mathematical Modelling of Bonded Marine Hoses for Single Point Mooring (SPM) Systems, with Catenary Anchor Leg Mooring (CALM) Buoy Application-A Review. J. Mar. Sci. Eng. 2021, 9, 1179. [CrossRef]

32. Le Cunff, C.; Ryu, S.; Duggal, A.; Ricbourg, C.; Heurtier, J.M.; Heyl, C.; Liu, Y.; Beauclair, O. Derivation of CALM Buoy coupled motion RAOs in Frequency Domain and Experimental Validation. In Proceedings of the Seventeenth International Offshore and Polar Engineering Conference, Lisbon, Portugal, 1-6 July 2007; Paper Number: ISOPE-I-07-402. ISOPE: Lisbon, Portugal, 2007; pp. 1-8. Available online: https://www.sofec.com/wp-content/uploads/white_papers/2007-ISOPE-Derivation-of-CALMBuoy-Coupled-Motion-RAOs-in-Frequency-Domain.pdf (accessed on 23 January 2022).

33. Zhang, S.-F.; Chen, C.; Zhang, Q.-X.; Zhang, N.-M.; Zhang, F. Wave Loads Computation for Offshore Floating Hose Based on Partially Immersed Cylinder Model of Improved Morison Formula. Open Pet. Eng. J. 2015, 8, 130-137. [CrossRef]

34. ABS. Rules for Building and Classing-Single Point Moorings; American Bureau of Shipping: Houston, TX, USA, 2021; Available online: https://ww2.eagle.org/content/dam/eagle/rules-and-guides/current/offshore/8_rules-forbuildingandclassingsingl epointmoorings_2021/spm-rules-jan21.pdf (accessed on 13 November 2021).

35. API. API RP 2SK-Design and Analysis of Stationkeeping Systems for Floating Structures, 3rd ed.; American Petroleum Institute (API): Texas, TX, USA, 2005.

36. API. API 17K-Specification for Bonded Flexible Pipe. ISO 13628-10 (Identical), Petroleum and Natural Gas Industries-Design and Operation of Subsea Production Systems-Part 10: Specification for Bonded Flexible Pipe, 3rd ed.; American Petroleum Institute (API): Texas, TX, USA, 2017.

37. OCIMF. Guide to Manufacturing and Purchasing Hoses for Offshore Moorings (GMPHOM); Witherby Seamanship International Ltd.: Livingstone, UK, 2009.

38. DNVGL. DNVGL-RP-F205 Global Performance Analysis of Deepwater Floating Structures; Det Norske Veritas \& Germanischer Lloyd: Oslo, Norway, 2017.

39. DNVGL. DNVGL-OS-E403. Offshore Laoding Buoys; Det Norske Veritas \& Germanischer Lloyd: Oslo, Norway, 2016; Available online: https:/ / rules.dnv.com/docs/pdf/DNV/os/2015-07/DNVGL-OS-E403.pdf (accessed on 13 November 2021).

40. Bridgestone, J. Study of Causes of Kinking in Floating Hoses at Petrobras/Tefran Terminal. Report No. 6YMT-0011; Bridgestone: Kurume, Japan, 1976.

41. Brown, M.; Elliott, L. A design tool for static underbuoy hose-systems. Appl. Ocean Res. 1987, 9, 171-180. [CrossRef]

42. OCIMF. A Study into Crane Loads Associated with Hose Handling at Offshore Terminals, OCIMF Info Paper, Version 6; Oil Companies International Marine Forum (OCIMF): London, UK, 2020; Available online: https://www.ocimf.org/media/58339/OC_INFOP APER2961_CRANE_V6.pdf (accessed on 14 February 2021).

43. Liu, B.; Fu, D.; Zhang, Y.; Chen, X. Experimental and numerical study on the wave force calculation of a partially immersed horizontal cylindrical float. Int. J. Nav. Arch. Ocean Eng. 2020, 12, 733-742. [CrossRef]

44. Roveri, F.E.; Volnei, L.S.S.; Cicilia, F.B. A Case Study on the Evaluation of Floating Hose Forces in a C.A.L.M. System. In Proceedings of the Twelfth International Offshore and Polar Engineering Conference, Kitakyushu, Japan, 26-31 May 2002; ISOPE: Lisbon, Portugal, 2002; pp. 190-197. Available online: https://www.academia.edu/26568632/A_Case_Study_on_the_Evaluation _of_Floating_Hose_Forces_in_a_C.A.L.M._System (accessed on 21 January 2022).

45. Ryu, S.; Duggal, A.S.; Heyl, C.N.; Liu, Y. Prediction of Deepwater Oil Offloading Buoy Response and Experimental Validation. Int. J. Offshore Polar Eng. 2006, 16, 1-7. Available online: https://www.sofec.com/wp-content/uploads/white_papers/2006-ISO PE-Prediction-of-DW-Oil-Offloading-Buoy-Response.pdf (accessed on 21 January 2022).

46. Ricbourg, C.; Berhault, C.; Camhi, A.; Lecuyer, B.; Marcer, R. Numerical and Experimental Investigations on Deepwater CALM Buoys Hydrodynamics Loads. In Proceedings of the Offshore Technology Conference Proceeding, Houston, TX, USA, 1-4 May 2006; OnePetro: Houston, TX, USA, 2006; pp. 1-8, OTC 18254-P. [CrossRef] 
47. Quash, J.E.; Burgess, S. Improving underbuoy hose system design using relaxed storm design criteria. In Proceedings of the Offshore Technology Conference, Houston, TX, USA, 30 April-3 May 1979; OnePetro: Houston, TX, USA, 1979; pp. $1827-1836$. [CrossRef]

48. Brady, I.; Williams, S.; Golby, P. A study of the Forces Acting on Hoses at a Monobuoy Due to Environmental Conditions. In Proceedings of the Offshore Technology Conference Proceeding, Dallas, TX, USA, 6-8 May 1974; OnePetro: Houston, TX, USA, 1974; pp. 1-10, OTC 2136.

49. Saito, H.; Mochizuki, T.; Fukai, T.; Okui, K. Actual measurement of external forces on marine hoses for SPM. In Proceedings of the Offshore Technology Conference, Houston, TX, USA, 6-8 May ; OnePetro: Houston, TX, USA, 1980; pp. 89-97, OTC 3803. [CrossRef]

50. Young, R.A.; Brogren, E.E.; Chakrabarti, S.K. Behavior of Loading Hose Models in Laboratory Waves and Currents. In Proceedings of the Offshore Technology Conference, Houston, TX, USA, 6-8 May 1980; pp. 421-428, OTC-3842-MS. [CrossRef]

51. Amaechi, C.V.; Wang, F.; Ye, J. Investigation on Hydrodynamic Characteristics, Wave-Current Interaction and Sensitivity Analysis of Submarine Hoses Attached to a CALM Buoy. J. Mar. Sci. Eng. 2022, 10, 120. [CrossRef]

52. Duggal, A.; Ryu, S. The dynamics of deepwater offloading buoys. In WIT Transactions on The Built Environment; Paper FSI05026FU; WIT Press: Singapore, 2005; Available online: https://www.witpress.com/Secure/elibrary/papers/FSI05/FSI05026FU.pdf (accessed on 21 January 2022).

53. O'Donoghue, T.; Halliwell, A. Vertical bending moments and axial forces in a floating marine hose-string. Eng. Struct. 1990, 12, 124-133. [CrossRef]

54. O'Donoghue, T.; Halliwell, A.R. Floating Hose-Strings Attached to a Calm Buoy. Available online: https://onepetro.org/OTC ONF/proceedings-abstract/88OTC/All-88OTC/OTC-5717-MS/49540 (accessed on 21 January 2022). [CrossRef]

55. Ziccardi, J.J.; Robins, H.J. Selection of the hose systems for SPM tanker terminals. In Proceedings of the Offshore Technology Conference (OTC), Houston, TX, USA, 21-23 April 1970. OTC-1152-MS. [CrossRef]

56. Amaechi, C.V.; Wang, F.; Ye, J. Understanding the fluid-structure interaction from wave diffraction forces on CALM buoys: Numerical and analytical solutions. Ships Offshore Struct. 2022. [CrossRef]

57. Amaechi, C.V.; Wang, F.; Ye, J. Numerical studies on CALM buoy motion responses and the effect of buoy geometry cum skirt dimensions with its hydrodynamic waves-current interactions. Ocean Eng. 2021, 244, 110378. [CrossRef]

58. Kang, Z.; Zhang, C.; Ni, W.; Xu, X. Research on Hydrodynamic Calculation Method of Deepwater CALM Buoy. In Proceedings of the 27th International Ocean and Polar Engineering Conference, San Francisco, CA, USA, 25-30 June 2017; pp. 217-224. Available online: https:/ / onepetro.org/ISOPEIOPEC/proceedings-abstract/ISOPE17/ All-ISOPE17/ISOPE-I-17-144/17298 (accessed on 21 January 2022).

59. Edward, C.; Dev, A.K. Assessment of CALM Buoys Motion Response and Dominant OPB/IPB Inducing Parameters on Fatigue Failure of Offshore Mooring Chains. In Practical Design of Ships and Other Floating Structures. PRADS 2019. Lecture Notes in Civil Engineering; Okada, T., Suzuki, K., Kawamura, Y., Eds.; Springer: Singapore, 2021; Volume 64. [CrossRef]

60. Wang, D.J.; Sun, S.P. An Analytical Solution of Wave Exciting Loads on CALM Buoy with Skirt. Appl. Mech. Mater. 2013, 477-478, 254-258. [CrossRef]

61. Cozijn, J.L.; Bunnik, T.H.J. Coupled Mooring Analysis for a Deep water CALM Buoy. In Proceedings of the International Conference on Offshore Mechanics and Arctic Engineering (OMAE), Vancouver, BC, Canada, 20-25 June 2004; Volume 1, pp. 663-673. [CrossRef]

62. Cozijn, H.; Uittenbogaard, R.; Brake, E.T. Heave, Roll and Pitch Damping of a Deepwater CALM Buoy with a Skirt. In Proceedings of the International Society of Offshore and Polar Engineering Conference, Seoul, Korea, 19-24 June 2005; pp. 388-395. Available online: https://www.researchgate.net/publication/267364857_Heave_Roll_and_Pitch_Damping_of_a_Deepwater_CALM_Bu oy_with_a_Skirt (accessed on 22 December 2021).

63. Woodburn, P.; Gallagher, P.; Naciri, M.; Borleteau, J.-P. Coupled CFD Simulation of the Response of a Calm Buoy in Waves. In Proceedings of the ASME 2005 24th International Conference on Offshore Mechanics and Arctic Engineering, Halkidiki, Greece, 12-17 June 2005; Volume 3, pp. 793-803. [CrossRef]

64. Amaechi, C.V.; Wang, F.; Ye, J. An investigation on the vortex effect of a CALM buoy under water waves using Computational Fluid Dynamics (CFD). Inventions 2022, 7, 23. [CrossRef]

65. Monroy, C.; Ducrozet, G.; Bonnefoy, F.; Babarit, A.; Gentaz, L.; Ferrant, P. RANS Simulations of a Calm Buoy in Regular and Irregular Seas using the SWENSE Method. Int. J. Offshore Polar Eng. 2011, 21, 264-271. Available online: https:/ / hal.archives-ouv ertes.fr/hal-01145146/document (accessed on 13 November 2021).

66. Abbaszadeh, M.; Dehghan, M.; Khodadadian, A.; Heitzinger, C. Analysis and application of the interpolating element free Galerkin (IEFG) method to simulate the prevention of groundwater contamination with application in fluid flow. J. Comput. Appl. Math. 2019, 368, 112453. [CrossRef]

67. Mirsian, S.; Khodadadian, A.; Hedayati, M.; Manzour-Ol-Ajdad, A.; Kalantarinejad, R.; Heitzinger, C. A new method for selective functionalization of silicon nanowire sensors and Bayesian inversion for its parameters. Biosens. Bioelectron. 2019, $142,111527$. [CrossRef] 
68. Abbaszadeh, M.; Dehghan, M.; Khodadadian, A.; Noii, N.; Heitzinger, C.; Wick, T. A reduced-order variational multiscale interpolating element free Galerkin technique based on proper orthogonal decomposition for solving Navier-Stokes equations coupled with a heat transfer equation: Nonstationary incompressible Boussinesq equations. J. Comput. Phys. 2020, $426,109875$. [CrossRef]

69. Bluewater. Bluewater Turret Buoy- Technical Description; Bluewater Energy Services: Amsterdam, The Netherlands, 2011; Available online: https:/ / www.bluewater.com/wp-content/uploads/2013/04/digitale-brochure-TurretBouy-Tech-description.pdf. (accessed on 13 November 2021).

70. EDesign. Edinburgh Designs Ltd., Edinburgh, UK. 2016. Available online: http://www4.edesign.co.uk/product/wave-generati ng-software/ (accessed on 26 September 2021).

71. Zhang, D.; George, A.; Wang, Y.; Gu, X.; Li, W.; Chen, Y. Wave tank experiments on the power capture of a multi-axis wave energy converter. J. Mar. Sci. Technol. 2015, 20, 520-529. [CrossRef]

72. Zhang, D.; Aggidis, G.; Wang, Y.; McCabe, A.; Li, W. Experimental results from wave tank trials of a multi-axis wave energy converter. Appl. Phys. Lett. 2013, 103, 103901. [CrossRef]

73. Doyle, S.; Aggidis, G.A. Experimental investigation and performance comparison of a 1 single OWC, array and M-OWC. Renew. Energy 2020, 168, 365-374. [CrossRef]

74. MARINET D2 27 Manual of Wave Instrumentation Survey of Laboratories. WP2: Marine Energy System Testing-Standardisation and Best Practice. MARINET (Marine Renewables Infrastrcuture Network for Emerging Energy Technologies). 2015. Available online: https:/ / www.marinet2.eu/wp-content/uploads/2017/04/D2.27-Manual-of-Wave-Instrumentation-1.pdf (accessed on 13 November 2021).

75. Imetrum Digital Image Correlation in Video Gauge ${ }^{\mathrm{TM}}$. 2017. Available online: https://www.imetrum.com/documents/productsheets / digital-image-correlation.pdf (accessed on 24 April 2021).

76. Imetrum. Video Gauge User Manual: Version 5.4.0.; Imetrum Limited: Bristol, UK, 2016; pp. 1-153.

77. Milad, M.; Green, S.; Ye, J. Mechanical properties of reinforced composite materials under uniaxial and planar tension loading regimes measured using a non-contact optical method. Compos. Struct. 2018, 202, 1145-1154. [CrossRef]

78. Aboshio, A.; Green, S.; Ye, J. Experimental investigation of the mechanical properties of neoprene coated nylon woven reinforced composites. Compos. Struct. 2014, 120, 386-393. [CrossRef]

79. Odijie, A.C. Design of Paired Column Semisubmersible Hull. Ph.D. Thesis, Lancaster University, Lancaster, UK, 2016. [CrossRef]

80. NI. LabView: Getting Started with LabView; National Instruments: Austin, TX, USA, 2003; Available online: https://www.ni.com/p df/manuals/323427a.pdf (accessed on 6 January 2022).

81. Klinger, T. Image Processing with LabVIEW and IMAQ Vision, 1st. ed.; National Instruments Virtual Instrumentation Series; Prentice Hall Professional: Upper Saddle River, NJ, USA, 2003.

82. WIT. WIT Motion User Manual. WIT Motion (Xingji Jia Yuan), Shenzhen City, Guangdong Province, China. 2019. Available online: https:/ / wiki.wit-motion.com/english (accessed on 26 September 2021).

83. WIT. Wit Motion Bluetooth Sensor. WIT Motion (Xingji Jia Yuan), Shenzhen City, Guangdong Province, China. 2020. Available online: http:/ / www.wit-motion.com/english.php (accessed on 26 September 2021).

84. Samsung. Samsung Galaxy S8|S8+ Smartphone User Manual; Samsung Electronics America Inc.: Ridgefield Park, NJ, USA, 2017; Available online: http:/ / files.customersaas.com/files/Samsung_G950U_Galaxy_S8_User_Manual.pdf (accessed on 26 September 2021).

85. Samsung. Samsung Galaxy S8- Support, Warranty Information, Solutions Tips; Samsung Electronics America Inc.: Ridgefield Park, NJ, USA, 2021; Available online: https://www.samsung.com/uk/support/model/SM-G950FZVABTU/ (accessed on 26 September 2021).

86. AKASO. AKASO Action Camera EK7000 User Manual; Akaso Tech LLC: Frederick, MD, USA, 2020; Available online: https: / / www.akasotech.com/usermanual/detail?category=1\&product=11\&name=EK7000 (accessed on 26 September 2021).

87. Amaechi, C.V.; Wang, F.; Ye, J. Numerical Assessment on the Dynamic Behaviour of Submarine Hoses Attached to CALM Buoy Configured as Lazy-S under Water Waves. J. Mar. Sci. Eng. 2021, 9, 1130. [CrossRef]

88. Amaechi, C.V.; Wang, F.; Hou, X.; Ye, J. Strength of submarine hoses in Chinese-lantern configuration from hydrodynamic loads on CALM buoy. Ocean Eng. 2018, 171, 429-442. [CrossRef]

89. Amaechi, C.V.; Ye, J.; Hou, X.; Wang, F.-C. Sensitivity Studies on Offshore Submarine Hoses on CALM Buoy with Comparisons for Chinese-Lantern and Lazy-S Configuration OMAE2019-96755. In Proceedings of the 38th International Conference on Ocean, Offshore and Arctic Engineering, Glasgow, Scotland, 9-14 June 2019; Available online: https:/ / eprints.lancs.ac.uk/id/eprint/13 4404 (accessed on 24 April 2021).

90. Orcina. OrcaFlex Manual, Version 9.8; Orcina Ltd.: Ulverton, Cumbria, UK, 2014.

91. Orcina. OrcaFlex Manual, Version 11.0f [Electronic Online Version of Manual and Documentation); Orcina Ltd.: Ulverton, Cumbria, UK, 2022; Available online: https:/ / www.orcina.com/SoftwareProducts/OrcaFlex/Documentation/index.php (accessed on 4 January 2022).

92. Orcina. Orcaflex Documentation, Version 11.0f. 2021. Available online: https://www.orcina.com/webhelp/OrcaFlex/Default.ht m (accessed on 24 April 2021).

93. Wang, F.; Chen, J.; Gao, S.; Tang, K.; Meng, X. Development and sea trial of real-time offshore pipeline installation monitoring system. Ocean Eng. 2017, 146, 468-476. [CrossRef] 
94. Tracker Tracker Video Analysis and Modeling Tool- Tracker Home Page. 2016. Available online: https://physlets.org/tracker/ (accessed on 4 January 2022).

95. Tracker Tracker Video Analysis and Modeling Tool- Tracker 6.0.2. 2016. Available online: http://www.opensourcephysics.org/it ems / detail.cfm?ID=7365 (accessed on 4 January 2022).

96. Brown, D.; Hanson, R.; Christian, W. Tracker Video Analysis and Modeling Tool. O.S.P- Open Source Physics. 2016. Available online: https: / / www.compadre.org/osp/items/detail.cfm?ID=7365 (accessed on 4 January 2022). 